\title{
R\&D, IMPLEMENTATION AND STAGNATION: A SCHUMPETERIAN THEORY OF CONVERGENCE CLUBS
}

\author{
Peter Howitt \\ David Mayer-Foulkes \\ Working Paper 9104 \\ http://www.nber.org/papers/w9104 \\ NATIONAL BUREAU OF ECONOMIC RESEARCH \\ 1050 Massachusetts Avenue \\ Cambridge, MA 02138
}

August 2002

The authors wish to thank Philippe Aghion, Jess Benhabib and Steve Redding for helpful conversations. Useful comments were received from seminar participants at the 2001 NBER Summer Institute, Boston University, the University of Western Ontario, and the Canadian Institute for Advanced Research. The views expressed herein are those of the authors and not necessarily those of the National Bureau of Economic Research.

(C) 2002 by Peter Howitt and David Mayer-Foulkes. All rights reserved. Short sections of text, not to exceed two paragraphs, may be quoted without explicit permission provided that full credit, including $\odot$ notice, is given to the source. 
R\&D, Implementation and Stagnation: A Schumpeterian Theory of Convergence Clubs Peter Howitt and David Mayer-Foulkes

NBER Working Paper No. 9104

August 2002

JEL No. O0

\begin{abstract}
We construct a Schumpeterian growth theory consistent with the divergence in per-capita income that has occurred between countries since the mid 19th Century, and with the convergence that occurred between the richest countries during the second half of the 20th Century. The theory assumes that technological change underwent a transformation late in the 19th Century, associated with modern R\&D labs. Countries sort themselves into three groups. Those in the highest group converge to a steady state where they do leading edge $\mathrm{R} \& \mathrm{D}$, while those in the intermediate group converge to a steady state where they implement technologies developed elsewhere. Countries in both of these groups grow at the same rate in the long run, as a result of technology transfer, but inequality between them increases during the transition. Countries in the lowest group grow at a slower rate, with relative incomes that fall asymptotically to zero. Once modern R\&D has been introduced, a country may have only a finite window of opportunity in which to introduce the institutions that support it.
\end{abstract}

Peter Howitt

Department of Economics

Brown University

Providence, RI 02906

and NBER

peter_howitt@brown.edu
David Mayer-Foulkes

División de Economía

Centro de Investigación y Docencia Económicas

Carretera México Toluca 3655

01210 México, D.F, México 
"The greatest invention of the 19th Century was the invention of the method of invention." Alfred North Whitehead (1931, p. 98)

"Countries that are technologically backward have a potentiality for generating growth more rapid than that of more advanced countries, provided their social capabilities are sufficiently developed to permit successful exploitation of technologies already employed by the technological leaders." Moses Abramovitz (1986, p.225)

"Lack of investment in an area of expertise early on may foreclose the future development of a technical capability in that area." Wesley Cohen and Daniel Levinthal (1990, p.128)

\section{Introduction}

The cross-country distribution of per-capita income has widened dramatically since the 19th Century. Pritchett (1997) infers that the proportional gap in living standards between the richest and poorest countries grew more than five-fold from 1870 to 1990, in what he calls "divergence, big-time." According to the tables in Maddison (2001) the proportional gap between the richest group of countries and the poorest ${ }^{1}$ grew from 3 in 1820 to 19 in 1998 . Quah $(1993,1997)$ finds evidence of emerging "twin peaks" in the cross-country income distribution continuing well into the second half of the 20th Century. Kremer et al. (2001) find that a single-peaked distribution may emerge but only after a prolonged transition. Mayer (2001) finds twin peaks in the distribution of life expectancy using the available data for 1962 to 1997.

A large number of empirical studies ${ }^{2}$ have shown that the large income differences that have emerged are mostly attributable to differences in productivity rather than to the differences in schooling and capital accumulation invoked by neoclassical growth theory. In particular, Feyrer (2001) finds that although the distribution of capital-output ratios is single-peaked, and the distribution of education levels is almost flat, the distribution of the productivity residual has become increasingly twin-peaked. These studies strongly suggest that the central factor beneath growing cross-country income disparities is technology.

There is however a major problem facing any technological explanation of divergence. Specifically, many studies ${ }^{3}$ show that a large group of countries have been converging to parallel growth

\footnotetext{
${ }^{1}$ The richest group was Western Europe in 1820 and the "Euopean Offshoots" (Australia, Canada, New Zealand and the United States) in 1998. The poorest group was Africa in both years.

${ }^{2}$ See for example Knight et al. (1993), Islam (1995), Caselli et al. (1996), Klenow and Rodriguez-Clare (1997), Prescott (1998), Hall and Jones (1999) and Easterly and Levine (2001).

${ }^{3}$ For example, Barro and Sala-i-Martin (1992), Mankiw et al. (1992) and Evans (1996).
} 
paths over the past 50 years or so. The tendency to convergence ${ }^{4}$ among rich countries is easy to understand as a manifestation of technology transfer. But what force was opposing technology transfer so as to produce the technological divergence that took place over the longer period from the mid 19th Century? And why did that force stop working during the second half of the 20th Century?

Moreover, this modern convergence group does not include all countries. In particular, the gap between the leading countries as a whole and the very poorest countries as a whole continued to widen throughout the second half of the 20th Century. For example, the proportional gap in per-capita income between Mayer's (2002) richest and poorest convergence groups grew by a factor of 2.6 between 1960 and 1995, and the proportional gap between Maddison's richest and poorest groups grew by a factor of 1.75 between 1950 and 1998. This raises the further question of why the forces that brought an end to the divergence among middle-to-high income countries did not also bring an end to the divergence between very rich and very poor countries. ${ }^{5}$

Our purpose here is to show how these questions can be addressed by modern Schumpeterian growth theory. To this end we propose a model of economic growth based on the multi-country model of Howitt (2000), which in turn is an extension of the Aghion-Howitt $(1992,1998)$ model of growth through creative destruction, and which implies a particular form of club-convergence. Specifically, in the earlier multi-country model all countries that continue to invest in new technologies eventually grow at the same rate, because they draw ideas from each other, whereas countries that do not invest in new technologies stagnate, because without making technology investments of their own they cannot benefit from technology transfer.

One problem with the earlier model of Howitt (2000) is that it does not take into account that different countries have used different strategies for tapping into the global technological frontier. Only a small handful of rich countries perform leading-edge R\&D. In 1996, for example, 5 countries accounted for over 80 percent of the world's formal R\&D expenditures, and 11 countries accounted

\footnotetext{
${ }^{4}$ We use the term "convergence" throughout to mean that countries approach parallel long-run growth paths. For emphasis we sometimes refer to the concept as "parallel convergence." Although the neoclassical growth model with instantaneous technology transfer exhibits parallel convergence, nevertheless the concept is not the same as the more familiar "conditional convergence," which means (Galor, 1996) that countries with the same characteristics converge to the same growth path. For example, in the case of multiple steady states of the sort illustrated in Figure 3 below, countries with the same characteristics but different initial conditions could converge to different growth paths (an example of club-convergence) but these paths would all be parallel. Conversely, in a model of conditional convergence, countries with one set of characteristics could all converge to a growth path that was not parallel to the common asymptotic path of countries with a different set of characteristics. Thus parallel convergence does not imply and is not implied by the usual concept of conditional convergence.

5 (Except for a small number of formerly poor "miracle" countries such as Botswana, China, Mauritius and the East Asian NICs).
} 
for over 95 percent. $^{6}$ Yet not all of the other countries stagnated relative to the frontier. As Evenson and Westphal (1995) document, a country cannot keep up with the frontier merely by copying technologies developed in leading countries, because technological knowledge is often tacit and circumstantially sensitive. Therefore countries that avoided stagnation without performing leading edge R\&D must have made significant technology investments to learn, modify, adapt and implement technologies that were originally developed elsewhere.

These technology investments in follower countries share many features with the R\&D activity that takes place in leading countries, in that they are costly, they build on knowledge developed elsewhere, their effects are random, and when successful they result in innovations - products or processes that were previously not feasible in that country. But they are not the same as leadingedge $R \& D$. Instead they are closer to the production process, involve less basic science, generate fewer spillovers to other countries, and generally contain a smaller element of novelty and a larger element of dependency on preceding innovations.

Another problem with the earlier model is that although there is considerable evidence for club-convergence, ${ }^{7}$ not even those countries at the bottom of the distribution have been completely stagnant technologically as the earlier model implies. According to Maddison's (2001) tables, percapita income in the poorest group of countries (Africa) grew by 60 percent from 1950 to 1998 . What is needed to account for the record of very poor countries is a model in which a country that invests in technological change can have a long-run growth rate that is positive but strictly less than the rate of growth of the leading countries, despite the fact that technology transfer is constantly exerting a force towards parallel convergence.

The present model deals with these two problems by taking into account two central features of technological change not considered by Howitt (2000). First, we distinguish between two types of technological investment, corresponding to the different strategies that countries have for tapping into the global technology frontier, namely "modern R\&D" and "implementation." The former (which for brevity we refer to as simply "R\&D") is what goes on in the most technologically advanced countries, while the latter is the process of assimilation and adaptation that takes place in less advanced countries. We suppose that both kinds of technology investment are costly, and both draw on the world's technology frontier, but R\&D draws more heavily on scientific knowledge and its institutions, and thus requires higher skill levels than implementation. In particular, graduating

\footnotetext{
${ }^{6}$ These calculations are made using data from Global Development Finance \& World Development Indicators and the Penn World Tables 5.6.

${ }^{7}$ Baumol (1986), Durlauf and Johnson (1995), and Mayer (2001, 2002).
} 
from implementation to $R \& D$ requires surpassing a threshold skill level that increases with the demands of new, ever advancing, leading technologies.

The second central feature we take into account is that a country's ability to acquire the skills used intensively in technology investment depends on its level of development, relative to the global technological frontier from which it draws new ideas. Thus a given time input into schooling/training will produce few effective skills in a country that is technologically backward, because learning takes place in an environment where modern technology is relatively unfamiliar, teachers are not as well versed in modern techniques, classrooms and labs are less up-to-date, and so forth. Therefore as the world's technological frontier advances, a country that does not keep pace will find it increasingly difficult to catch up by absorbing foreign knowledge, because its skill levels will not be keeping up with the frontier. As a result its technology investments will become increasingly ineffective. ${ }^{8}$

This erosion of absorptive capacity that takes place when a country falls behind is a central part of our explanation of long-term divergence. It weakens the force of technology transfer that is tending to bring about parallel convergence. Followers of Gerschenkron (1952) have argued that technological backwardness conveys an advantage, because the ability to make use of frontier ideas raises the potential size of the advance that can be made by investing in technological change. This advantage will be present in the model to be developed below, but the erosion of absorptive capacity constitutes a counteracting disadvantage to technological backwardness.

Our central hypothesis is that the activity we call R\&D was made possible in the late 19th Century by the introduction of the modern R\&D lab that exploited the growing interconnections between science and technology, and by the existence of various institutions such as government research labs and agencies, scientific academies, universities with close ties to industry and commerce, and so forth. ${ }^{9}$ Before this, all technological change took the form of a pragmatic creativity that we have loosely characterized as technological implementation.

The introduction of modern $R \& D$ was the fundamental driving force behind the emergence of large income disparities. It worked by creating a fundamental change in the dynamic evolution of global productivity differences, resulting in three distinct converge groups as illustrated in Figure

\footnotetext{
${ }^{8}$ See Benhabib and Spiegel (1994) and Griffith et al. (2001) for evidence that skills are an important determinant of a country's absorptive capacity.

${ }^{9}$ Edison's research lab in Menlo Park, generally considered the first modern "invention factory," opened in 1876. Rosenberg and Birdzell (1986, ch.8) provide a brief account of the rise of the modern R\&D lab and the increasing interconnectedness between science and technology, which they argue began around 1875. Mowery and Rosenberg (1998, ch.2) and Wright (1999) argue that a network of linkages between universities, government agencies and commercial enterprises played a key role in establishing America's technological leadership in many fields.
} 


\section{A sketch of our argument goes as follows.}

Suppose modern $R \& D$ is introduced at time $t_{0}$. Until then all countries were on parallel growth paths, with some level-differences attributable to differences in country-specific parameters. Figure 1 depicts the evolution of productivity in three countries, one in each convergence group. Country A has the "best" parameter values (i.e. those most favorable to growth) and country C the worst. After $t_{0}$ only those countries whose productivity level is above some critical value will have a skilled enough labor force to begin using modern R\&D immediately. (In Figure 1 this is only country A.) Those that do will start growing faster as a result of using the more productive (R\&D) method of technology investment. All others will continue using implementation, and will start to fall further behind country A.

As the other countries fall further behind, technology transfer will start to pull their growth rates up, but until their growth rates have caught up with the growth rate of the frontier, the erosion of absorptive capacity engendered by their increasing technological backwardness will tend to weaken the force of technology transfer. In countries that are not too far behind to start with, absorptive capacity will remain strong enough to eventually put them on growth paths parallel to that of country A, but with a permanently bigger gap in productivity levels, as in the case of country B; the initial gap that was due to different parameter values is now amplified by the fact that country A has adopted modern R\&D while country B has not. But if the country starts too far behind (as with country $\mathrm{C}$ ) then the erosion of absorptive capacity will weaken the force of technology transfer to such an extent that, although the country will continue to grow forever, its asymptotic growth rate will be strictly less than the common long-run growth rate of countries $\mathrm{A}$ and B.

The above account presumes that all countries with sufficient skill levels to engage in $R \& D$ also have the institutions required to support $R \& D$. If this is not the case then, once $R \& D$ takes hold in some leading economies, other economies may have a finite window of opportunity in which to establish the necessary institutions, and therefore to join the leading club. If this window is missed, absorptive capacity may erode to such an extent that the country will become trapped in technological implementation or even stagnation, and it will then take more than the right institutions to rejoin the leaders.

The model is consistent with the dynamical features observed by Feyrer (2001) who notes that the emergence of "twin peaks" in the distribution of world income is mainly attributable to diverging rates of total factor productivity growth rather than diverging levels of capital accumulation or 
education. (We abstract completely from capital accumulation and in our model time spent in education per person will be the same in each country.) As Feyrer notes, models constructing development traps based on multiple equilibria in physical capital accumulation (such as Becker and Barro, 1989; Murphy et al., 1989; Becker et al., 1990; Zilibotti, 1995; and Galor and Weil, 1996) or in human capital accumulation (such as Azariadis and Drazen, 1990; Tsiddon, 1992; Galor and Zeira, 1993; Durlauf, 1993, 1996; Benabou, 1996; and Galor and Tsiddon, 1997) are inconsistent with this observation.

The model is related to those of Basu and Weil (1998) and Acemoglu and Zilibotti (2001), in which follower countries are slow to adopt the leader's innovations because the technologies that are being developed by the leader are not "appropriate" for the factor proportions being used in production by the followers. In our model the followers are slow to adopt not because the technology is inappropriate but because adopting requires "tacit" knowledge ${ }^{10}$ which is less accessible the further removed is the adopter's everyday cultural and technological experience and skill level from that of the innovator. Also, these other models describe steady states with unchanging cross-country differences in productivity levels and identical growth rates, whereas we are trying to account for divergent productivity growth rates.

The model is also related to a long literature, beginning with Gerschenkron (1952), maintaining that institutional barriers are what prevent a country from catching up with technological leaders. Abramovitz (1986) for example believed that technological backwardness conveys a growth advantage by opening up the relatively easy path of adoption and imitation, but that "social backwardness" creates an offsetting disadvantage. In our model the values of the various parameters that determine the steady-state level of a country's growth path, and the presence or absence of the institutions necessary for supporting modern $\mathrm{R} \& \mathrm{D}$, might be considered as defining some relevant components of social backwardness. But in addition we argue that economic backwardness conveys disadvantages (by eroding absorptive capacity) as well as advantages.

Our approach is similar to that of Nelson and Phelps (1966), who argue that a country's productivity growth will be the product of a technology gap (to the world's technology leader) and an absorptive capacity term which is a function of domestic skill levels (see their equation (8)). In our model it is the product of a technology gap and the frequency of domestic innovations, the latter being dependent on the level of "innovation-effective" skills. (See equation (10) below.)

Parente and Prescott $(1994,1999)$ focus on legal and regulatory barriers to adopting foreign

\footnotetext{
${ }^{10}$ The importance of tacit knowledge for technological progress and development has been analyzed and documented by Arrow (1969) and Evenson and Westphal (1995).
} 
technology. Their model ignores the costs of technology adoption, arising from tacitness and circumstantial sensitivity, that make technology transfer less than automatic even in the absence of such barriers. It also focuses on steady-state differences in productivity levels, rather than on divergent productivity-growth rates. We see our model as being complementary with theirs, for one of the key country-specific parameters in our model determining convergence-group membership $(\phi)$ represents the extent to which the legal/regulatory environment favors the creation/adoption of new technology. Thus our model suggests that introduction of modern R\&D has leveraged the cross-country productivity differences due to adoption barriers that Parente and Prescott have estimated to be quantitatively very large.

Acemoglu et al. (2002) complement our analysis by explicitly modeling one specific mechanism by which inappropriate institutions can prevent a country from using the best method of R\&D. They focus, as do Parente and Prescott (1999), on monopoly rights, which they argue can be growth enhancing for a very backward country but can impede the switch from implementation to R\&D. The failure to switch prevents absolute convergence to the leader. However, they do not address the issue of how large gaps arose, and in their analysis all countries converge to parallel growth paths whether or not they adopt appropriate institutions.

Our model also gives an alternative explanation for the results obtained by Acemoglu et al. (2001). In their study, a mortality variable constructed for the colonial era serves as an instrument for modern institutions, explaining a substantial proportion of modern differences in income. The authors argue that early settler mortality was amongst the determinants of the characteristics of colonial states, ranging from extractive states to "Neo-Europes" (Crosby, 1986), that this status determined their early institutions, especially with regard to property rights and checks against government power, that the institutions have persisted over time, and that the persistent institutions continue to affect economic growth.

We provide an alternative interpretation of their results, which does not rely upon an unexplained persistence of institutions. By their reasoning, colonial mortality and early institutions can be expected to be correlated with the country-specific parameters determining which convergence group it joined when modern R\&D was introduced, specifically the efficiency of resource allocation (the parameter $\psi$ below), and the incentives to save (the parameter $\tau$ ) and to innovate $(\phi)$. The long-term character of these effects results not from institutional persistence but from their effects on human capital and technology dynamics. Our "window of opportunity" result shows that the economic differences caused by colonial experience can persist even if the institutions do not. 
Section 2 below lays out our basic model, under the assumption that there is just one method for investing in technological change. It uses this model to analyze the determinants of the world growth rate and of each country's relative productivity, both in and out of steady state, before the introduction of modern R\&D. Section 3 then shows what happens if we start in the steady state and introduce modern R\&D, assuming that some countries can use the new method but some lack the necessary skill levels. It shows how countries sort themselves into the three convergence groups depicted in Figure 1, under the assumption that all countries have in place the institutions that are needed to support R\&D. Section 4 then addresses the question of what happens if these institutions are not in place in every country, and shows how this can create windows of opportunity. Section 5 contains our concluding remarks.

\section{The basic model}

Consider a world economy with $m$ different countries, connected to each other through a flow of technological ideas. For simplicity we ignore all other relationships between countries and assume they do not exchange products or factors of production with each other. We begin by analyzing an isolated country, in which there is just one method of technology investment; that is, before the introduction of modern R\&D. There is a unit mass of individuals, each with linear intertemporal preferences in consumption, and a constant rate of time preference $\rho>0$.

\subsection{Production}

There is a single final output, produced by intermediate products, according to the production function:

$$
Y_{t}=\psi \int_{0}^{1} A_{t}(i) G\left(x_{t}(i)\right) d i
$$

where $\psi$ is a country-specific efficiency parameter representing the combined effects of the country's institutions, policies, geography, and all other factors influencing total factor productivity except for technological knowledge; $x_{t}(i)$ is the country's input of intermediate product $i$ into producing final output at $t ; G$ is a smooth production kernel with positive but diminishing marginal product; and $A_{t}(i)$ is a country-specific technology parameter reflecting the productivity of intermediate product $i$ in the country at time $t$.

Each intermediate product is produced by skills, according to the production function:

$$
x_{t}(i)=S_{t}^{M}(i) / A_{t}(i)
$$


where $S_{t}^{M}(i)$ is the input of skills into manufacturing in sector $i$ at $t$. Division by $A_{t}(i)$ in $(1)$ indicates that successive vintages of the intermediate product are produced by increasingly skillintensive techniques. Each intermediate product is produced by a local monopolist, who operates with a price schedule given by the marginal product function $p_{t}(i)=\psi A_{t}(i) G^{\prime}\left(x_{t}(i)\right)$ and a cost function $w_{t} A_{t}(i) x_{t}(i)$, where $w_{t}$ is the market-determined (and country-specific) price of skills in terms of the numeraire, final output.

Since each intermediate firm's marginal revenue and marginal cost schedules are proportional to $A_{t}(i)$, and since firms differ only in their value of $A_{t}(i)$, they all choose to supply the same quantity of intermediate product: $x_{t}=x_{t}(i)$ for all $i$. Thus:

$$
x_{t}(i)=x_{t}=S_{t}^{M} / A_{t}
$$

where $S_{t}^{M}$ is the total demand for skills in manufacturing and $A_{t}$ is the average productivity parameter across all sectors in the country. ${ }^{11}$ Substituting from (2) into the profit-maximization condition of each intermediate firm yields the demand function for skills in manufacturing:

$$
S_{t}^{M}=A_{t} \widetilde{s}\left(\omega_{t}\right)
$$

where $\widetilde{s}$ is a decreasing function ${ }^{12}$ of the (country-specific) "efficiency-adjusted" price of skills:

$$
\omega_{t} \equiv w_{t} / \psi
$$

Each local monopolist earns a flow of profits proportional to its productivity parameter $A_{t}(i)$, namely:

$$
\pi_{t}(i)=A_{t}(i) \psi \widehat{\pi}\left(\omega_{t}\right)
$$

where the function ${ }^{13} \widehat{\pi}$ is decreasing in $\omega_{t}$.

\subsection{Supply of skills}

Each individual acquires skills by spending time in "education," which we broadly interpret to include training. Someone who spends the fraction of time $e_{t}$ in education at $t$ (and the fraction $1-e_{t}$ working in either manufacturing or technology investment) attains a skill level:

$$
F_{t}=A_{t} f\left(e_{t}\right) ; \quad f^{\prime}>0, f^{\prime \prime} \leq 0, f(0)=0
$$

\footnotetext{
${ }^{11}$ From (1), the definition of $A_{t}$ and the adding-up condition we have: $S_{t}^{M}=\int_{0}^{1} A_{t}(i) x_{t} d i=A_{t} x_{t}$. Equation (2) follows directly.

${ }^{12}$ For example, in the Cobb-Douglas case where $G(x) \equiv x^{\alpha}$ we have $\widetilde{s}(\omega)=\left(\omega / \alpha^{2}\right)^{\frac{1}{\alpha-1}}$.

${ }^{13}$ In the Cobb Douglas case of footnote 12 we have $\widehat{\pi}(\omega)=\frac{1-\alpha}{\alpha} \omega\left(\omega / \alpha^{2}\right)^{\frac{1}{\alpha-1}}$.
} 
where $A_{t}$ is again the economy-wide average productivity parameter and $f$ is a production function representing the technology of skill-acquisition. The level of $A_{t}$ matters because of a human-capital externality; that is, time spent acquiring skills is more valuable in a technologically more advanced economy where there is more to learn from others. ${ }^{14}$

To simplify the dynamics we assume that skill acquisition takes place so much faster than technological progress that we can treat it as being instantaneous. Thus a person who spends the fraction of time $e_{t}$ in education at date $t$ to acquire the skill-level $F_{t}$ will earn an income of $w_{t} F_{t}\left(1-e_{t}\right)$ per unit of time. The person will maximize income by choosing $e_{t}$ equal to the constant:

$$
\widehat{e} \equiv \arg \max f(e)(1-e)
$$

independently of $w_{t}$ and $A_{t}$, and will supply the amount:

$$
S_{t}=\widehat{\sigma} A_{t}
$$

of skills per unit of time to the market, where:

$$
\widehat{\sigma} \equiv f(\widehat{e})(1-\widehat{e})
$$

\subsection{Technological change}

As in other Schumpeterian growth models, technology investment is targeted at specific intermediate products, results in a random sequence of innovations, and is performed by firms that are not already producing. As in Howitt (2000), we introduce an element of technology transfer by assuming that each innovation creates an improved version of the existing product, with a productivity parameter that equals the world-wide "leading-edge technology parameter:"

$$
A_{t}^{\max } \equiv \max \left\{A_{j t}(i) \mid i \in[0,1], j=1, \ldots, m\right\}
$$

where the $j$ subscript denotes a variable specific to country $j$. The innovator becomes the new incumbent producer until replaced by the next innovator in that industry in that country. Note that this way of introducing technology transfer makes it analogous to and symmetrical with the intersectoral technology spillovers occurring within a country, for the quality $A_{t}^{\max }$ of an innovation depends on the most advanced technology in any sector of any country.

\footnotetext{
${ }^{14}$ What matters is that skills depend positively on the economy's technology level, not that this dependency involves an externality. Thus we could have assumed instead that skill production involves a material input whose price is independent of $\omega_{t}$. We chose the present alternative for its relative simplicity.
} 
The inputs to technology investment are skills and final output. Since the costs and benefits of this investment are the same in each sector, we assume that it is carried out at the same rate in each sector. The Poisson arrival rate $\mu_{t}$ of an innovation in any sector (also the economy-wide continuous flow of innovations) is determined by a constant-returns production function, which is more skill-intensive than the production function for final output:

$$
\mu_{t}=\lambda\left(S_{t}^{R}\right)^{\beta} z_{t}^{1-\beta} / A_{t}^{\max } \quad 0<\beta<1
$$

where $S_{t}^{R}$ is the input of skills into technology investment, $z_{t}$ is the material input of the final good into technology investment, and $\lambda$ is the productivity of the innovation process. The division by $A_{t}^{\max }$ takes into account the force of increasing complexity; as technology advances, the resource cost of further advances increases proportionally.

Let $V_{t}$ be the value (to the innovator) of an innovation at time $t$. Suppose that technology investments are subsidized at the proportional rate $\phi<1$. The country-specific parameter $\phi$ is a proxy for all distortions and policies that impinge directly on the incentive to innovate. It can be negative, in which case the distortions and policies favoring innovation are outweighed by those discouraging it. ${ }^{15}$ Then a firm investing in technology at $t$ will maximize its expected profit:

$$
\mu_{t} V_{t}-(1-\phi)\left(w_{t} S_{t}^{R}+z_{t}\right)
$$

subject to (4). This implies the arbitrage condition: ${ }^{16}$

$$
(1-\phi) \zeta w_{t}^{\beta}=\lambda V_{t} / A_{t}^{\max }
$$

where $\zeta \equiv \beta^{-\beta}(1-\beta)^{\beta-1} \cdot{ }^{17}$ It also implies that:

$$
\mu_{t}=\lambda w_{t}^{1-\beta} \xi S_{t}^{R} / A_{t}^{\max }
$$

where $\xi \equiv(\beta \zeta)^{-1}$.

By substituting for $S_{t}^{R}$ in (6) from the market-clearing condition for skills:

$$
A_{t} \widehat{\sigma}=A_{t} \widetilde{s}\left(\omega_{t}\right)+S_{t}^{R}
$$

\footnotetext{
${ }^{15} \mathrm{An}$ increase in $\phi$ can be thought of as a reduction of the "barriers to adoption" stressed by Parente and Prescott (1994, 1999), because technology transfer and innovation are all part of the same process in this model.

${ }^{16}$ We assume that there is always an equilibrium with a positive skill input to technology investment. (See footnote 23 below for further details). Otherwise (5) would have to be replaced by a pair of complementary Kuhn-Tucker inequalities.

${ }^{17}$ Condition (5) follows from the fact that $\zeta \omega^{\beta}$ is the unit cost function associated with the production function $\left(S^{R}\right)^{\beta} z^{1-\beta}$.
} 
we can express the equilibrium rate of innovation as:

$$
\mu_{t}=\lambda \psi^{1-\beta} \widetilde{\mu}\left(\omega_{t}\right) a_{t}
$$

where $a_{t} \equiv A_{t} / A_{t}^{\max }$ denotes the country's "normalized" productivity, and where $\widetilde{\mu}$ is an increasing function ${ }^{18}$ of $\omega_{t}$.

To interpret (7) note first that a higher efficiency-adjusted price $\omega_{t}$ implies a lower demand for skills in manufacturing and hence a larger supply to the technology investment sector; it also implies that material input to technology investment will increase more than in proportion to the now relatively more expensive skill input, and hence that the rate of innovation will also increase more than in proportion. Next, a higher normalized productivity $a_{t}$ implies that with a given amount of education each worker engaged in technology investment will be supplying more skills relative to the world technology frontier and hence will produce innovations at a faster rate. Conversely, a lower value of $a_{t}$ means that the country is technologically more "backward", and the resulting decrease in the frequency of innovations implied by (7) is the disadvantage of backwardness referred to in Section 1 above.

\subsection{The price of skills}

The value $V_{t}$ of an innovation is the expected present value of all the profits from now until the next innovation in the same sector, at which time the firm will be replaced as the incumbent monopolist in the sector: ${ }^{19}$

$$
V_{t}=\int_{t}^{\infty} e^{-\int_{t}^{u}\left(r+\mu_{s}\right) d s} A_{t}^{\max } \psi \widehat{\pi}\left(\omega_{u}\right) d u
$$

where $r$ is the rate of interest. Differentiating both sides with respect to $t$ produces the analogue to the Bellman equations of Aghion and Howitt (1992):

$$
\dot{V}_{t} / V_{t}-\dot{A}_{t}^{\max } / A_{t}^{\max }=r+\mu_{t}-\psi \widehat{\pi}\left(\omega_{t}\right) A_{t}^{\max } / V_{t}
$$

Suppose that saving is taxed at the constant marginal rate $\tau \in[0,1)$. Then

$$
r=\frac{\rho}{1-\tau} .
$$

The country-specific parameter $\tau$ is intended to proxy for all those aspects of the regulatory and institutional environment impinging on the incentive to save, such as security of property rights, etc.

\footnotetext{
${ }^{18}$ Specifically: $\widetilde{\mu}\left(\omega_{t}\right) \equiv \omega_{t}^{1-\beta} \xi\left(\widehat{\sigma}-\widetilde{s}\left(\omega_{t}\right)\right)$.

${ }^{19}$ We assume that the previous incumbent is unable to re-enter once it stops producing. That is why a successful innovator can ignore potential competition from previous innovators in the same product. Howitt and Aghion (1998, Appendix) show that the alternative case in which the previous incumbent is free to reenter produces the same steady-state comparative-statics results in a related closed-economy model.
} 
It follows from $(5)$ and $(7) \sim(9)$ that the efficiency-adjusted price of skills $\omega_{t}$ obeys the differential equation:

$$
\frac{d \omega_{t}}{d t}=\left[\frac{\omega_{t}}{\beta}\right]\left[\frac{\rho}{1-\tau}+\lambda \psi^{1-\beta}\left(\widetilde{\mu}\left(\omega_{t}\right) a_{t}-\frac{\tilde{\pi}\left(\omega_{t}\right)}{1-\phi}\right)\right]
$$

where $\tilde{\pi}$ is a decreasing function ${ }^{20}$ of $\omega_{t}$.

\subsection{Technology transfer and absorptive capacity}

We have modelled technological innovation and technology transfer as two aspects of the same technology investment activity, reflecting the fact that every act of innovation builds on previous ideas. $^{21}$ Specifically, each innovation allows the innovator to access a worldwide technological frontier. Let $g_{t}$ denote the growth rate of this frontier:

$$
g_{t} \equiv \dot{A}_{t}^{\max } / A_{t}^{\max }
$$

Although $g_{t}$ will be endogenous to the whole model, for now we take it as given.

A country's average productivity parameter $A_{t}$ grows as a result of innovations, each of which replaces the pre-existing parameter $A_{t}(i)$ in a sector by $A_{t}^{\max }$. Thus the average increase in technology parameters across all innovating sectors at $t$ is the difference $A_{t}^{\max }-A_{t}$. The rate of increase of the average equals the rate of innovation $\mu_{t}$ times this average increase:

$$
\dot{A}_{t}=\mu_{t}\left(A_{t}^{\max }-A_{t}\right)
$$

which together with (7) implies:

$$
\frac{\dot{A}_{t}}{A_{t}}=\left(\frac{A_{t}^{\max }-A_{t}}{A_{t}}\right) \mu_{t}=\left(a_{t}^{-1}-1\right) \lambda \psi^{1-\beta} \widetilde{\mu}\left(\omega_{t}\right) a_{t}
$$

The two effects of $a_{t}$ on the right-hand side of (10) represent respectively the advantage and the disadvantage of backwardness as measured (inversely) by $a_{t}$. The advantage is that the further behind a country is the greater the average size of each innovation, as measured by the average proportional increase $\frac{A_{t}^{\max }-A_{t}}{A_{t}} \equiv a_{t}^{-1}-1$. This is the factor emphasized by followers of Gerschenkron. The disadvantage is that the further behind (given the efficiency-adjusted price of skills $\omega_{t}$ ) the smaller the frequency of innovations $\mu_{t}=\lambda \psi^{1-\beta} \widetilde{\mu}\left(\omega_{t}\right) a_{t}$. This results from erosion of absorptive capacity as explained above.

According to (10) there is an overall advantage to backwardness, since the RHS is proportional to $1-a_{t}$. But whether or not this overall advantage is sufficient to ensure that a follower country

\footnotetext{
${ }^{20}$ Specifically, $\widetilde{\pi}\left(\omega_{t}\right) \equiv \frac{\widehat{\pi}\left(\omega_{t}\right)}{\zeta \omega_{t}^{\beta}}$.

${ }^{21}$ Cohen and Levinthal (1989) and Griffith et al. (2001) provide empirical support for this two-sided nature of technology investment.
} 
ends up growing at the same rate as a leader depends on the other factors involved in determining the follower's frequency of innovations. In particular it will depend on the equilibrium value of the efficiency-adjusted price of skills $\omega_{t}$ in the follower country.

To see this, suppose $\omega_{t}$ and $g_{t}$ are both constant. Then (10) and the definitions of $a_{t}$ and $g_{t}$ imply:

$$
\dot{a}_{t} / a_{t}=\left(1-a_{t}\right) \lambda \psi^{1-\beta} \widetilde{\mu}(\omega)-g
$$

so that:

$$
a_{t} \rightarrow \max \left\{0,1-g / \lambda \psi^{1-\beta} \widetilde{\mu}(\omega)\right\}
$$

Since $\widetilde{\mu}$ is an increasing function, this implies that when the steady-state value of $\omega$ is too small the country's growth rate will converge to a value ${ }^{22}$ strictly less than the world growth rate $g$, whereas when $\omega$ is large enough the growth rate will converge to $g$. In the former case, as the country falls further behind the leader (as $a_{t}$ falls), the country's absorptive capacity becomes too small to prevent its normalized productivity $a_{t}$ from falling to zero despite the increasing size of innovations. In the latter case absorptive capacity remains high enough that normalized productivity is stabilized at a strictly positive value.

\subsection{The dynamical system}

It follows that the evolution of a country's normalized productivity $a_{t}$ and its efficiency-adjusted price of skills $\omega_{t}$ are governed by a two-dimensional dynamical system:

$$
\begin{aligned}
\frac{d a_{t}}{d t} & =a_{t}\left[\left(1-a_{t}\right) \lambda \psi^{1-\beta} \widetilde{\mu}\left(\omega_{t}\right)-g_{t}\right] \\
\frac{d \omega_{t}}{d t} & =\left[\frac{\omega_{t}}{\beta}\right]\left[\frac{\rho}{1-\tau}+\lambda \psi^{1-\beta}\left(\widetilde{\mu}\left(\omega_{t}\right) a_{t}-\frac{\widetilde{\pi}\left(\omega_{t}\right)}{1-\phi}\right)\right]
\end{aligned}
$$

These equations, together with an initial condition on $a_{0}$, a transversality condition on $\omega_{t}$ deriving from its connection (5) with the value $V_{t}$ of an innovation, and a given time path for $g_{t}$ determine a unique time path for $\left(a_{t}, \omega_{t}\right)$ from 0 to $\infty$.

The phase diagram for a constant growth rate $g>0$ is shown in Figure $2 .{ }^{23}$ Note that $\omega_{t}$ is a forward-looking jump-variable in this perfect foresight system; that is, $\omega_{t}$ is a translation of the forward-looking expected value of an innovation, using the research arbitrage equation (5). The

\footnotetext{
${ }^{22}$ Specifically: $\lambda \psi^{1-\beta} \widetilde{\mu}(\omega)$.

${ }^{23}$ The critical value $\underline{\omega}$ of the efficiency-adjusted skill price depicted in Figure 2 is the value at which all skills would be absorbed by the manufacturing sector. It is defined by the equation: $\widetilde{s}(\underline{\omega})=\widehat{\sigma}$. As long as $\omega$ remains above $\underline{\omega}$ then our assumption of an interior solution to the research-arbitrage equation is warranted.
} 
diagram is constructed for given values of the parameters $\phi, \psi$ and $\tau$, so an increase in $\omega_{t}$ can be interpreted as a ceteris paribus increase in the value of an innovation.

The $\dot{a}=0$ locus shows how steady-state productivity depends upon the price of skills. To see why it is upward sloping note that, as explained in the previous paragraph, an increase in $\omega$ corresponds to an increase in the value of an innovation, which induces a temporarily faster rate of innovation, which leads to a higher steady-state level of productivity relative to the global leading edge $A_{t}^{\max }$. The $\dot{\omega}=0$ locus shows how the steady-state price of skills depends on productivity. It is downward sloping because the larger is the country's normalized productivity the greater is the rate of innovation in any industry (because of the higher level of skills relative to the global technology frontier), hence the higher the rate of creative destruction and the shorter the expected duration of incumbency of a monopolist, hence the smaller the expected value of an innovation and the lower the steady-state demand price for skills in technology investment.

There is a unique steady state, exhibiting the usual saddle-path property. At each date the country's GDP equals the sum of labor income and profit income:

$$
Y_{t}=\omega_{t} S_{t}+A_{t} \psi \widehat{\pi}\left(\omega_{t}\right)=A_{t}\left(\omega_{t} \widehat{\sigma}+\psi \widehat{\pi}\left(\omega_{t}\right)\right)
$$

Since $\omega_{t}$ is constant in the steady state, therefore the long-run growth rate of GDP is the steady state productivity growth rate:

$$
\lim _{t \rightarrow \infty} \dot{A}_{t} / A_{t}=\left(1-a^{*}\right) \lambda \psi^{1-\beta} \widetilde{\mu}\left(\omega^{*}\right)
$$

There are two different kinds of steady state, for the reasons discussed in section 2.5 above. Figure $2 \mathrm{a}$ shows the case of an interior steady-state, in which $a_{t} \rightarrow a^{*}>0$, and the country's long-run growth rate equals $g$. All economies for which there exists such an equilibrium will be on parallel growth paths in the long run, as a result of technology transfer.

Figure $2 \mathrm{~b}$ shows the case in which there is long-run growth but at a rate below that of the global technology frontier, because $\lambda \psi^{1-\beta} \widetilde{\mu}\left(\omega^{*}\right)<g$. Productivity and GDP fall to zero relative to the countries in an interior equilibrium, because absorptive capacity becomes too low to keep up with the frontier.

We suppose that before the introduction of modern R\&D every country is in an interior steady state, with $a^{*}>0$. As illustrated in Figure 1, all countries will be on strictly parallel growth paths, growing at the same rate $g>0$. 


\subsection{Growth of the world economy}

As in other innovation-based endogenous growth models, the growth rate $g_{t}$ of the world's leadingedge technology parameter $A_{t}^{\max }$ is determined by a spillover process that constitutes part of the mechanism of technology transfer (the other part being the use of $A_{t}^{\max }$ by innovators in every country). That is, the global technology frontier expands as a result of innovations everywhere, which produce knowledge that feeds into technology investment in other sectors and in other countries. Specifically:

$$
g_{t}=\sum_{j=1}^{m} \sigma_{j} \mu_{j t}
$$

where the spillover coefficients $\sigma_{j}$ are all non-negative.

For simplicity, assume that there is one leading country, country 1, generating all the spillovers. Then:

$$
g_{t}=\sigma_{1} \mu_{1 t}
$$

Using (7) to replace $\mu_{1 t}$ and substituting into (11) for the leading country shows that its normalized productivity converges ${ }^{24}$ asymptotically and monotonically to the steady-state value:

$$
a_{1}^{*}=\frac{1}{1+\sigma_{1}} .
$$

The leader's steady-state skill price $\omega_{1}^{*}$ is determined by (14) and the other steady-state condition:

$$
1-\phi_{1}=\frac{\lambda \psi_{1}^{1-\beta} \widetilde{\pi}\left(\omega_{1}^{*}\right)}{\frac{\rho}{1-\tau_{1}}+\lambda \psi_{1}^{1-\beta} \widetilde{\mu}\left(\omega_{1}^{*}\right) a_{1}^{*}}
$$

which follows from (12) and is analogous to the steady-state research arbitrage equations analyzed in Aghion and Howitt (1998). The steady-state growth rate of the global technology frontier is:

$$
g=\sigma_{1} \lambda \psi_{1}^{1-\beta} \widetilde{\mu}\left(\omega_{1}^{*}\right) a_{1}^{*}
$$

\subsection{Comparative statics of the steady state}

The steady-state growth rate $g$ of the global technological frontier depends on the leading country's parameter values, according to:

Proposition 1 The steady-state global growth rate $g$ is an increasing function of the leading country's efficiency parameter $\psi_{1}$, its innovation-subsidy rate $\phi_{1}$ and the innovation-productivity parameter $\lambda$. It is a decreasing function of the leading country's saving-tax rate $\tau_{1}$.

\footnotetext{
${ }^{24}$ Spefically, $a_{t}$ must evolve according to:

$$
\dot{a}_{1 t}=a_{1 t}\left[1-a_{1 t}\left(1+\sigma_{1}\right)\right] \lambda \psi_{1}^{1-\beta} \widetilde{\mu}\left(\omega_{1 t}\right) .
$$
}


Proposition 1 is a fairly standard application of Schumpeterian growth theory to a closed economy. It follows directly from equations $(14) \sim(16)$. Note that the positive effect of the efficiency parameter $\psi_{1}$ depends critically on our assumption that skills are not the only factor of production in innovation - i.e. that $\beta<1$. That is, although an increase in $\psi_{1}$ increases the incentive to innovate by raising the equilibrium level of profit income in the leading economy, it also increases the cost of innovation by raising the equilibrium price of skills in manufacturing. If skills were the only input to innovation then the cost and reward would be increased in the same proportion and so would the equilibrium price of skills, so there would be no change in the equilibrium level of technology investment in the leading country and the growth rate would remain unchanged. ${ }^{25}$

For every other country, the steady-state values of $a$ and $\omega$ can be derived from the equations:

$$
\begin{aligned}
1-\phi & =\frac{\lambda \psi^{1-\beta} \widetilde{\pi}(\omega)}{\frac{\rho}{1-\tau}+\lambda \psi^{1-\beta} \widetilde{\mu}(\omega) a} \\
a & =1-\frac{g}{\lambda \psi^{1-\beta} \widetilde{\mu}(\omega)}
\end{aligned}
$$

describing the two stationary loci of Figure 2 above. The country's steady-state normalized productivity depends on the same country-specific parameters whose values in the leading country determine the growth rate $g$, and in the same direction. Thus we have:

Proposition 2 Each non-leading country's steady-state normalized productivity $a^{*}$ is an increasing function of its efficiency parameter $\psi$, its innovation-subsidy rate $\phi$ and the innovation-productivity parameter $\lambda$. It is a decreasing function of its saving-tax rate $\tau$ and the growth rate $g$ of the global technology frontier.

The economic interpretation of these results is straightforward. Starting from a steady state any parameter change that would have lead to a higher growth rate in a closed economy will raise the equilibrium rate of innovation, causing the country's average productivity to grow faster than $g$ for some period of time. But the resulting decrease in the gap $a_{t}^{-1}-1$ will reduce the average size of innovations, thus bringing the rate of productivity growth back down. (This is just the technology transfer effect discussed in section 2.5 above, working in reverse.) Eventually productivity growth will return to its original rate $g$ but with a permanently higher value of $a$. Also, an increase in the world growth rate $g$ will first cause the country's average productivity to fall further behind the global frontier, until technology transfer stabilizes $a$ at a permanently lower value.

\footnotetext{
${ }^{25}$ The logic of this argument is the same as that of Howitt and Aghion (1998), who show that a subsidy to capital accumulation will have a positive long-run effect on growth except in the limiting case where $\beta=1$.
} 


\section{The introduction of modern R\&D}

The rise of modern economic growth following the first Industrial Revolution was closely associated with the emergence of the scientific way of thought. ${ }^{26}$ A new perspective of nature, founded on the scientific achievements of a new set of institutions, sustaining ever deeper advances of knowledge, brought about a new era of technological change. From a technological point of view, this movement culminated in the late 19th Century with the introduction of the modern R\&D lab, and the growing scientific content of technological change.

Accordingly, we assume that until some date $t_{0}$ productivity advances were based on a pragmatic creativity occurring close to the production process, with innovation-productivity $\lambda$. Thereafter, an alternative technology for R\&D emerged, intimately linked with the scientific revolution and its institutions, with innovation-productivity $\lambda^{\prime}>\lambda$.

To be viable, however, the new technology requires workers with a skill level at least equal to some threshold value $\gamma A_{t}^{\max }$, which depends upon the global technology frontier. It also requires a set of supporting institutions, such as research-oriented universities, government R\&D agencies and research labs, and close links between academia, government and commerce. If workers do not have this threshold level of skills then R\&D yielding leading-edge technological innovation is impossible, although the original process of pragmatic creativity remains. In the presence of scientific knowledge and advanced technologies this pragmatic process of innovation now takes on the character of technological implementation.

Other than different $\mathrm{R} \& \mathrm{D}$ productivities $\left(\lambda^{\prime}\right.$ instead of $\left.\lambda\right)$ and different skill requirements and institutional requirements, we assume that $R \& D$ and implementation work exactly the same way. In particular, both involve an element of technology transfer because whichever method is used to make an innovation, the innovation consists of a new intermediate product embodying the leading edge technology parameter $A_{t}^{\max }$. Thus in a country satisfying the minimal skill and institutional requirements, the conversion from implementation to $R \& D$ can be represented simply by an increase in the innovation-productivity parameter from $\lambda$ to $\lambda^{\prime}$.

We assume throughout this section that all countries have in place the institutions necessary to support modern R\&D. ${ }^{27}$ Therefore any country for which $F_{t} \geq \gamma A_{t}^{\max }$, or equivalently:

$$
a_{t} \geq \frac{\gamma}{f(\widehat{e})}
$$

will be able to engage in $R \& D$ at date $t$. We suppose that this is the case for the leader in its initial

\footnotetext{
${ }^{26}$ See Jacob (1997).

${ }^{27}$ In section 4 below we examine what happens if some countries are missing these institutions at first.
} 
steady-state:

$$
\frac{1}{1+\sigma_{1}}>\frac{\gamma}{f(\widehat{e})}
$$

Therefore the leader will go immediately to a new equilibrium, with an unchanged normalized productivity $a_{1}=1 /\left(1+\sigma_{1}\right)$. According to Proposition 1 the growth rate of the global technology frontier will increase to $g^{\prime}>g$.

\subsection{Skill acquisition}

Any other country satisfying (19) in the original steady state will also be able to use the method of R\&D. Indeed even if its normalized average productivity falls short of satisfying (19) it might pay people to acquire enough extra skills so that they can engage in R\&D rather than implementation. Specifically, define

$$
\sigma_{c}\left(\gamma / a_{t}\right) \equiv \max \left\{f(e)(1-e) \mid f(e) \geq \gamma / a_{t}\right\}
$$

and note that by construction:

$$
\sigma_{c}\left(\gamma / a_{t}\right) \leq \widehat{\sigma} \text { with equality if and only if } f(\widehat{e}) \geq \gamma / a_{t} \text {. }
$$

A worker that chooses to supply skills to R\&D will supply the amount $\sigma_{c}\left(\gamma / a_{t}\right)$ per unit of time.

Suppose that workers are offered a price $w_{t}^{\prime}$ per unit for supplying their skills to R\&D or $w_{t}$ for supplying them elsewhere (to implementation or manufacturing). They will all choose to work in $\mathrm{R} \& \mathrm{D}$ if they can make strictly more income there than elsewhere; i.e. if $w_{t}^{\prime} \sigma_{c}\left(\gamma / a_{t}\right)>w_{t} \widehat{\sigma}$. In equilibrium some skills must be supplied to manufacturing. Therefore:

$$
w_{t}^{\prime} / w_{t} \leq \widehat{\sigma} / \sigma_{c}\left(\gamma / a_{t}\right) \text { with strict equality if } \mathrm{R} \& \mathrm{D} \text { occurs. }
$$

Since anyone who can work in $\mathrm{R} \& \mathrm{D}$ can also work elsewhere:

$$
w_{t}^{\prime} / w_{t} \geq 1 \text { if } \mathrm{R} \& \mathrm{D} \text { occurs. }
$$

\subsection{R\&D or implementation?}

The research arbitrage equation (5) for implementation must now be replaced by the Kuhn-Tucker inequality:

$$
(1-\phi) \zeta w_{t}^{\beta} \geq \lambda V_{t} / A_{t}^{\max } \text { with strict equality if implementation occurs }
$$

while the research arbitrage equation for $\mathrm{R} \& \mathrm{D}$ is:

$$
(1-\phi) \zeta\left(w_{t}^{\prime}\right)^{\beta}=\lambda^{\prime} V_{t} / A_{t}^{\max } .
$$


Therefore:

$$
w_{t}^{\prime} / w_{t} \leq\left(\lambda^{\prime} / \lambda\right)^{1 / \beta} \text { with strict equality if implementation occurs. }
$$

It follows that there are three distinct regions for the historically given value of $a_{t}$ :

1. If $a_{t} \geq \gamma / f(\widehat{e})$ then no one needs to undertake any extra schooling to be able to work in R\&D, so they will continue to supply the unconstrained income-maximizing flow of productivityadjusted skills $\widehat{\sigma}$ to the market. Only R\&D will take place, because $\lambda^{\prime}>\lambda$ implies that the payoff to $R \& D$ is strictly higher than the payoff to implementation. There will be a single price of skills in the economy, satisfying the research arbitrage equation (23) for R\&D. ${ }^{28}$

2. If $a_{t}<\gamma / f(\widehat{e})$ and $\left(\lambda^{\prime} / \lambda\right)^{1 / \beta} \geq \widehat{\sigma} / \sigma_{c}\left(\gamma / a_{t}\right)$ then only R\&D will take place in equilibrium. ${ }^{29}$ Workers who upgrade their skills levels to $\gamma A_{t}^{\max }$ will earn a skill premium that just compensates them for the extra time spent in education. The price of skills in $R \& D$ will be given by the research arbitrage equation (23), while the price of skills in manufacturing will be given by the arbitrage condition:

$$
w_{t}=\frac{\sigma_{c}\left(\gamma / a_{t}\right)}{\widehat{\sigma}} w_{t}^{\prime}
$$

that makes workers indifferent between acquiring the unconstrained income-maximizing skill level $A_{t} f(\widehat{e})$ and working in manufacturing or acquiring the minimal skill level $\gamma A_{t}^{\max }$ to work in $R \& D$.

3. If $a_{t}<\gamma / f(\widehat{e})$ and $\left(\lambda^{\prime} / \lambda\right)^{1 / \beta}<\widehat{\sigma} / \sigma_{c}\left(\gamma / a_{t}\right)$ then only implementation will occur in equilibrium, there will be a single price $w_{t}$ for skills in the economy, given by the research arbitrage equation (5), and everyone will continue to supply the unconstrained income-maximizing flow of productivity-adjusted skills $\widehat{\sigma}$ to the market. No one will find it worthwhile spending time to upgrade skills to the minimum level needed for R\&D because the increase in the relative price $\left(w_{t}^{\prime} / w_{t}\right)=\left(\lambda^{\prime} / \lambda\right)^{1 / \beta}$ would not compensate for the reduction in available supply $\sigma_{c}\left(\gamma / a_{t}\right) / \widehat{\sigma}$ implied by the extra time in education.

\footnotetext{
${ }^{28}$ More formally, in this case (20) and (21) imply that $w_{t}^{\prime} \leq w_{t}$. This, together with (24) and the fact that $\lambda^{\prime}>\lambda$ imply that no implemenation can occur. Therefore all technology investment takes the form of innovation, and (22) implies that $w_{t}^{\prime}=w_{t}$.

${ }^{29}$ In the borderline case where the weak inequality holds with strict equality then the equilibrium mix between implementation and $R \& D$ is indeterminate, but it turns out that the overall rate of innovation at that point is independent of the mix. So with no effect on the system dynamics to be described below, we assume that even in this borderline case there will be no implementation, just R\&D.
} 


\subsection{The dynamics of a follower country}

In region 3 a country will continue to behave after the introduction of modern R\&D just the same way as it did before, but now facing a higher value of the global growth rate. The country's dynamics will continue to be governed by (11) and (12), with $g_{t}$ equal to $g^{\prime}$ instead of $g$.

In region 1 a country will behave as before, but with two changes. Not only will it face the higher global growth rate, but also the price of skills will now obey the new research arbitrage equation (23) instead of (5). Since the only difference between these equations is the value of $\lambda$, the country's dynamics in this region will be the same as in region 3 but with $\lambda$ replaced by $\lambda^{\prime}$.

In region 2 the change goes beyond a change in one or two parameters because in this region, as we saw in the preceding section, there will be a segmented labor market. Let $\chi_{t}$ be the equilibrium fraction of people that choose to work in manufacturing. Then the supply of skills to manufacturing will be $\chi_{t} A_{t} \widehat{\sigma}$. In equilibrium this supply must equal the demand for skills in manufacturing:

$$
\chi_{t} \widehat{\sigma}=\widetilde{s}\left(\omega_{t}\right) .
$$

Thus the supply of skills to R\&D from the remaining fraction $1-\chi_{t}$ will be:

$$
S_{t}^{R}=\left(1-\chi_{t}\right) A_{t} \sigma_{c}\left(\gamma / a_{t}\right)=\left(\frac{\widehat{\sigma}-\widetilde{s}\left(\omega_{t}\right)}{\widehat{\sigma}}\right) A_{t} \sigma_{c}\left(\gamma / a_{t}\right) .
$$

By analogy to (6) the overall rate of innovation will be:

$$
\mu_{t}=\lambda^{\prime}\left(w_{t}^{\prime}\right)^{1-\beta} \xi S_{t}^{R} / A_{t}^{\max }
$$

Putting these results together with (25) we have:

$$
\mu_{t}=\left(\frac{\sigma_{c}\left(\gamma / a_{t}\right)}{\widehat{\sigma}}\right)^{\beta} \lambda^{\prime} \psi^{1-\beta} \widetilde{\mu}\left(\omega_{t}\right) a_{t} .
$$

Thus the country's dynamics obey:

$$
\begin{aligned}
\frac{d a_{t}}{d t} & =a_{t}\left[\left(1-a_{t}\right)\left(\frac{\sigma_{c}\left(\gamma / a_{t}\right)}{\widehat{\sigma}}\right)^{\beta} \lambda^{\prime} \psi^{1-\beta} \widetilde{\mu}\left(\omega_{t}\right)-g^{\prime}\right] \\
\frac{d \omega_{t}}{d t} & =\left[\frac{\omega_{t}}{\beta}\right]\left[\frac{\rho}{1-\tau}+\left(\frac{\sigma_{c}\left(\gamma / a_{t}\right)}{\widehat{\sigma}}\right)^{\beta} \lambda^{\prime} \psi^{1-\beta}\left(a_{t} \widetilde{\mu}\left(\omega_{t}\right)-\frac{\widetilde{\pi}\left(\omega_{t}\right)}{1-\phi}\right)\right]
\end{aligned}
$$

which is the same as in region 1 except for the additional term $\left(\frac{\sigma_{c}\left(\gamma / a_{t}\right)}{\widehat{\sigma}}\right)^{\beta}$ in both equations. 


\subsection{The effects of modern R\&D on a follower country}

The three regions can be pieced together continuously as shown in Figure 3. The border between regions 1 and 2 is defined by the condition that (19) hold with equality, whereas the border between regions 2 and 3 is defined by the condition that:

$$
\left(\lambda^{\prime} / \lambda\right)^{1 / \beta}=\widehat{\sigma} / \sigma_{c}(\gamma / a)
$$

As before, the $\dot{\omega}=0$ locus is everywhere downward sloping. ${ }^{30}$ The $\dot{a}=0$ locus is upward sloping in regions 1 and 3 but not necessarily in region 2. Thus there is a possibility of multiple steady states, as depicted in Figure 3, where one implementation steady state and two R\&D steady states exist, all of them with $a^{*}>0$. Intuitively, a country with low normalized productivity will be unable to access modern $\mathrm{R} \& \mathrm{D}$, which will keep its normalized productivity from rising, while one with high normalized productivity can access the means of keeping it high. Generically, the odd numbered steady states are well-behaved saddle points and the even numbered ones are unreachable sources.

There are also two possible kinds of non-R\&D steady states. In Figure 3 there is an "implementation" steady state with $a^{*}>0$ and a growth rate equal to the world rate $g$. Figure 4 shows a case where there is a unique "stagnation" steady-state, with $a^{*}=0$, as in Figure $2 \mathrm{~b}$ above, and a growth rate strictly less than $g$. In both of these non-R\&D steady states all technology investment takes the form of implementation rather than $R \& D$. The only difference between the implementation steady state and the stagnation steady state is whether or not the countries absorptive capacity remains strong enough to keep up with the technological frontier.

How the introduction of modern R\&D affects a country's growth path depends on which region it was in to begin with. From Figure 3 it is clear that if a country's initial steady state is in region 1, and there is a steady state in region 1 after the introduction of modern $R \& D$, then the system must converge to that new steady state, where all technology investment takes the form of R\&D. The qualitative change in such a country's steady-state normalized productivity $a^{*}$ can be analyzed by changing $g$ to $g^{\prime}$ and $\lambda$ to $\lambda^{\prime}$ in the steady-state equations (17) and (18). As Proposition 2 indicates, the increase in $g$ tends to reduce $a^{*}$ while the increase in $\lambda$ tends to raise it, so the overall effect on $a^{*}$ is ambiguous. (In region 1 , the increase in $g$ shifts the $\dot{a}=0$ locus to the left without altering the $\dot{\omega}=0$ locus, while the increase in $\lambda$ shifts both loci to the right.) In the case of the leader country, as we have seen, the overall effect is to leave $a^{*}$ unchanged. By continuity there will be almost no effect on $a^{*}$ in a country whose parameter values are close to those of the leader.

\footnotetext{
${ }^{30}$ To see that it is downward-sloping in regime 2, note that, by construction, the function $\sigma_{c}$ in equation (27) is non-increasing.
} 
At the other extreme, a country that starts with its initial steady state in region 3 must converge to a new steady-state in region 3 , where all $\mathrm{R} \& \mathrm{D}$ takes the form of implementation. This is because in region 3 the effect of introducing modern $\mathrm{R} \& \mathrm{D}$ is to shift the $\dot{a}=0$ curve to the left, with no change in the $\dot{\omega}=0$ locus. Thus if the initial steady state is in region 3 then there is also a new steady state in region 3 , with smaller $a^{*}$ and larger $\omega^{*}$. As Figure 5 indicates, this can be an interior equilibrium, as in Figure 2a above, where the country continues to grow at the same rate $g^{\prime}$ as the leader country. But if the economy starts with too small a normalized productivity, and the increase in $g$ is large enough, then the $\dot{a}=0$ locus will shift by so much that it no longer has an interior intersection with the $\dot{\omega}=0$ locus, and the new steady state will be a degenerate equilibrium with $a^{*}=0$ and a growth rate strictly less than $g^{\prime}$, as discussed earlier in section 2.6 and illustrated in Figure 2b.

Thus even though all countries are assumed to have started in the same interior steady-state equilibrium, growing at the common rate $g$, the rise in world growth instigated by the introduction of modern R\&D will create three groups, in three distinct steady-state equilibria, as illustrated in Figure 1 above. ${ }^{31}$ More formally:

Proposition 3 Following the introduction of modern RED there are three different steady states that a country can converge to:

A) RED (region 1 or 2): All technology investment takes the form of REDD. The country grows at the same rate $g^{\prime}$ as the leader. Its normalized productivity $a^{*}$ can be greater or less than in the original steady state. The leader country converges to such a steady state, with an unchanged normalized productivity $a_{1}^{*}=1 /\left(1+\sigma_{1}\right)$.

B) Implementation (region 3, interior): All technology investment takes the form of implementation. The country grows at the same rate $g^{\prime}$ as the leader. Its normalized productivity $a^{*}$ is non-negative but the steady-state productivity gap $a_{1}^{*} / a^{*}$ between it and the leader country is larger than before.

C) Stagnation (region 3, corner): All technology investment takes the form of implementation. The country grows at a rate strictly less than $g^{\prime}$. The productivity gap between it and the leader country rises without bound.

The three groups referred to in Proposition 3 are defined in terms of their average productivity

\footnotetext{
${ }^{31}$ If we had begun with two groups (by assuming that initially there were some countries already in the stagnation steady state shown in Figure $2 \mathrm{~b}$ above) then the introduction of modern R\&D would still create the same three new groups. Moreover, the gap between the leader and the stagnating countries would start to widen even faster than before.
} 
parameters $A_{t}$. In terms of income per person (as defined by equation (13) above) those countries in the stagnation group $\mathrm{C}$ will have an asymptotic growth rate less than that of the leader, and those in the implementation group B will have the same asymptotic growth rate as the leader. It is not automatic however that the steady-state proportional income gap:

$$
\frac{Y}{Y_{1}}=(1+\sigma) a \frac{\omega \widehat{\sigma}+\psi \widehat{\pi}(\omega)}{\omega_{1} \widehat{\sigma}+\psi_{1} \widehat{\pi}\left(\omega_{1}\right)}
$$

necessarily rises between a country in group B and the leader, because the respective efficiencyadjusted skill prices $\omega$ and $\omega_{1}$ in the two countries will rise, which could conceivably offset the fall in a. However, it is easy to show that if the coefficient $\beta$ on skills in the innovation technology is close enough to zero (it is exactly zero in Howitt (2000)) then neither $\omega$ nor $\omega_{1}$ will be affected much by the change, so the fall in $a$ implies that this income gap will widen, just like the productivity gap.

\subsection{Sorting into convergence groups}

One advantage of this model is that not only does it explain how different convergence groups might form but it helps to identify which countries will belong to which group. The discussion immediately preceding Proposition 3, taken together with Proposition 2, suggests that those countries with relatively large values $\psi$ and $\phi$ and low values of $\tau$ will be most likely to be in group A, because those are most likely to have initial and final steady states in region 1. Likewise, among those countries whose initial steady state was in region 3 and who therefore will end up in group B or group $\mathrm{C}$, those with the lowest values of $\psi$ and $\phi$ and the highest values of $\tau$ will be those who join group C.

More precisely, take any country and consider what would have happened if its innovationsubsidy rate $\phi$ had been larger than it was, both before and after the introduction of modern R\&D. In terms of the phase diagram illustrated in Figures 3 and 4, the effect would have been to shift the $\dot{\omega}=0$ locus up for all values of $a$. Hence all the reachable steady states with $a>0$ would have been shifted to the right, and the values of $a$ for which $\dot{a}>0$ on the equilibrium saddle path would have been strictly augmented. As a result, starting from any given initial position, the country's new steady-state value of $a$ would have been at least as large as it is. Moreover, by Proposition 2, the country's initial value (the pre-modern steady-state value) of $a$ would have been larger than it is, which by itself would also have resulted in at least as large a new steady-state value.

Thus ceteris paribus, the larger is $\phi$ the larger (weakly) will be a country's new steady-state value of $a$. It follows that if two countries differ only in their values of $\phi$ and the country with the lower value joins the leading convergence group A then so does the other one; the former must have 
a new steady state in region 1 or 2 and hence so must the latter. Likewise if the country with the higher value stagnates, joining group $\mathrm{C}$ with $a \rightarrow 0$, then so must the other.

The same reasoning is valid if for an increase in $\phi$ we substitute an increase in the efficiency parameter $\psi$ or a decrease in the saving tax rate $\tau$, the only difference being that in the case of an increase in $\psi$ not only does the $\dot{\omega}=0$ locus shift up, the $\dot{a}=0$ locus also shifts down. The reasoning is also valid if we substitute for an increase in $\phi$ any combination of these three qualitative parameter changes. Thus we have:

Proposition 4 Consider any two countries belonging to different convergence groups.

1) If one country is converging to an RED steady state (group A) then:

(a) its efficiency parameter $\psi$ is larger than the other's,

(b) its innovation-subsidy rate $\phi$ is larger than the other's, or

(a) its saving-tax rate $\tau$ is smaller than the other's.

2) If one country is converging to a stagnation steady state (group C) then:

(a) its efficiency parameter $\psi$ is smaller than the other's,

(b) its innovation-subsidy rate $\phi$ is smaller than the other's, or

(a) its saving-tax rate $\tau$ is larger than the other's.

The importance of Proposition 4 is not only that it helps us to identify which country will belong to which group. In combination with Proposition 2 it also implies that the countries that converge to an R\&D steady state (group A) will tend to be those whose relative productivity was among the highest to begin with, and that those who converge to stagnation (group C) will tend to be those whose relative productivity was among the lowest to begin with. This is important because if there were a substantial cross-over of groups then the gap between the leader and those in the stagnation group could actually narrow for some time before eventually widening, so the model would not imply divergence, just multiple steady states.

In fact, most evidence suggests that there is a large positive correlation across countries in parameters that affect growth positively. Indeed this is one of the main obstacles to drawing inferences from cross-country growth regressions. If countries were ranked the same in terms of all three of the parameters then there would be no crossover at all following the introduction of modern R\&D: 
Corollary to Proposition 4 If the ranking of countries by efficiency parameters $\psi$ is the same as the ranking by innovation-subsidy rates $\phi$, and the inverse of the ranking by saving-tax rates $\tau$, then a country that is converging to an R\&D steady state (group A) started with a higher average productivity than one that is not, and a country that is converging to stagnation (group $C$ ) started with a lower average productivity than one that is not.

Intuitively, those countries with the greatest productivity to begin with will be those whose skills will be sufficiently advanced to use the new method of R\&D, and who will therefore join group A. Likewise those with the lowest productivity to begin with will be those in which absorptive capacity is already so low that further erosion caused by an acceleration of the frontier will tip them into joining group C, while those joining group B will tend to be those whose productivity was initially in the middle of the distribution - - too low to use the new technique of R\&D but high enough that even after some erosion they will have enough absorptive capacity to keep up with the technological frontier.

\section{Window of opportunity for lagging economies}

Suppose that some countries do not have in place the institutions to support modern $R \& D$ when it is introduced. Then there may be only a finite period of time - a window of opportunity - for the country to set up these institutions. After this, the erosion of its absorptive capacity induced by technological advance in the leading country will trap the lagging country in implementation or stagnation. This is illustrated in Figure 6, where we show a country whose parameter values are identical to those of the leading country, and where we assume the existence of three distinct equilibria as in Figure 3.

So long as the institutions supporting R\&D are not put into place in this country, it will follow a trajectory leading to the implementation steady state. Once R\&D becomes possible, a new R\&D steady state appears, at the original level of normalized productivity $1 /\left(1+\sigma_{1}\right)$. If this happens at time $t_{0}$, the country's path will be identical to the leading country's, and it will go immediately to the new R\&D steady state. As long as it happens before the country's normalized productivity has fallen below the critical value $\underline{a}$ defined by the new steady state in region 2 (as at $a_{t_{1}}$ in Figure 6) the decline will be reversed and the economy will go asymptotically to the same new R\&D steady state as the leading country. But if the new institutions are put into place after $a_{t}$ has descended below $\underline{a}$ (as at $a_{t_{2}}$ in Figure 6), it will continue to follow a path to the new implementation equilibrium. The example depicted in Figure 6 can be modified so that the steady state in region 
3 is an stagnation equilibrium as in Figure 2b, without changing the analysis. Thus we have our "window of opportunity" result:

Proposition 5 An economy may have a finite time period during which it can achieve an RED steady state by establishing the institutions supporting RESD, and after which it will be trapped in implementation or stagnation if has not yet established these institutions.

\subsection{Present Day Windows of Opportunity}

The history of the industrialization and development of several countries, amongst them Denmark, Sweden, Italy, Japan, Korea, Singapore and Ireland has been characterized by periods of high, sustained growth sometimes called miracle growth. Other countries, including Argentina, India, Nigeria, Brazil and Mexico have experienced long periods of sustained economic growth but then failed to reach the status of full development (see Ugo Pipitone, 1995 for a historical discussion of the first five and last four cases). These different phenomena may result from technological windows of opportunity that open up and then close at various times. We give an explanation of how this might occur.

The leading edge technological level $A_{t}^{\max }$ represents a mix of technologies. During the history of technological growth there has been a sequence of dominant or even general purpose technologies, such as the steam engine, electricity, trains, automobiles, telecommunication, plastics, chemical technologies, information, etc. These have different characteristic innovation productivities for implementation and $R \& D$ and different human capital requirement for $R \& D$. Thus, the parameters $\lambda, \lambda^{\prime}$ and $\gamma$ may shift over time, reflecting medium- to long-term changes in these productivities and requirements as the dominant technologies change. For example, technologies requiring for their implementation a higher level of skills for a larger proportion of the population in effect require a higher human capital threshold level.

What this means is that the critical values for the existence of a low-technology trap may change. If implementation becomes relatively easier, the trap may disappear for countries with better scientific institutions and parameters for growth. To the extent that they increase the world growth rate $g_{t}$ (of $A_{t}^{\max }$ ), however, their success may strengthen the implementation trap for other countries, which will not experience the window of opportunity.

If a country is originally in region 3 (implementation) and opportunity appears to transit to the higher equilibrium (either because scientific institutions were put into place in time or because changes in parameters led to the disappearance of the low technology trap), it will first continue 
implementing and then begin innovating, a well-known pattern in the case of, for example, the Asian growth miracles. Bloom and Williamson (1998) show how growth in these countries coincided with a demographic window of opportunity in which a lower dependency ratio increased the saving rate. Our model provides a reason why not all countries reaching the demographic window of opportunity will develop: they might not find themselves in a position to reach the high technology steady state.

Similarly, the advent of a new technology for which implementation is more difficult may push some countries into stagnation, by making implementation unprofitable. Alternatively, the exhaustion of the easy part of a new technology may close a transition window that may have been open, by raising the threshold levels necessary for $\mathrm{R} \& \mathrm{D}$. A whole set of countries could experience a period of sustained growth followed by a period of low growth.

Although the competition of ideas is enough for miracles in some countries to diminish the opportunity for miracles in others, trade in the products which are the subject of technological advance probably strengthens this effect, by discouraging production and innovation in less prepared countries in precisely those technologies which more prepared countries are using to grow.

According to our model, the emergence of Asia, together with the arrival of the general purpose information technologies, could be contributing factors for the lost decades of growth in Latin America, and its consequent permanence in an implementation equilibrium, and for the permanence of Africa in a stagnation equilibrium. Maloney (2002) has used this framework to compare the development of Latin America with countries such as Australia, Sweden and Finland, finding that deficient human capital accumulation determining technological capabilities may have played a role in its failure to develop.

\section{Conclusions}

We model skill acquisition and technological dynamics when technology investment can take the form of modern $\mathrm{R} \& \mathrm{D}$ or technological implementation. This dichotomy, kept alive by the ever larger skill-level necessary for $R \& D$, gives rise to three convergence clubs, characterized respectively by R\&D, implementation and stagnation. Applied to the origin of 20th Century growth, the model explains the simultaneous emergence of large income inequalities between countries. It also implies that after an initial widening of the distribution the most advanced countries (not just those that perform leading-edge R\&D) should converge to parallel growth paths, in line with the empirical findings of the convergence literature. Technology transfer is powerful enough to bring about this degree of convergence between the $\mathrm{R} \& \mathrm{D}$ and implementation clubs, but it is not powerful enough 
to overcome the erosion of absorptive capacity causing divergence between the stagnation club and others. Once R\&D takes off, the erosion of absorptive capacity in laggard countries implies that only a finite window of opportunity may exist for them to set up the scientific institutional supports of modern R\&D, so as to join the leading countries in development.

It remains to incorporate physical capital accumulation into the analysis, and to see what difference the degree of capital mobility makes. Our preliminary analysis suggests that the results are robust to capital accumulation. It also suggests that capital mobility tends to amplify the disadvantage of backwardness that is central to our analysis. That is, capital tends to move away from technologically more backward areas and toward the frontier; through a scale effect this reduces the incentive to innovate in the laggard country, causing it to fall even further behind the leader technologically.

The model is consistent with a highly demanding set of facts pertaining to the current distribution of income and factors of production among countries. It also is consistent with the persistence of relative economic conditions since the colonial era. It explains why economic miracles are possible in modern-day windows of opportunity for development and also why whole sets of countries may be simultaneously afflicted with prolonged periods of slow economic growth when technological implementation becomes more difficult.

Economic policy aimed at fostering growth should stress technological change and skill acquisition. Facilitating technological implementation, opening knowledge flows, fostering knowledge institutions and promoting human capital investment are key factors for increasing productivity. Once good rates of technological implementation are achieved, well-targeted policies may make it easier to identify and overcome specific thresholds constituting obstacles for technological change, thus dissipating low-technology traps. At an average rate of growth of $2 \%$, only 33 countries lagged less than 50 years behind the U.S. in 1995, while the bottom 73 countries in the World Bank data base were more than a century behind. Perhaps the appropriate human capital and technological policies can produce not just parallel economic growth and poverty alleviation but economic miracles.

However, once a country has missed its windows of opportunity, it faces a more difficult task than before, because creating the conditions for an R\&D steady state to exist is no longer sufficient for the steady state to be reached. At this point, a "big push" is needed to reverse the erosion of absorptive capacity and join the leading convergence club. Whether or not a poor country is capable of engineering the push on its own remains an important open question. 


\section{References}

Abramovitz, Moses. "Catching Up, Forging Ahead, and Falling Behind." Journal of Economic History 46 (June 1986): 385-406.

Acemoglu, Daron, Philippe Aghion, and Fabrizio Zilibotti. "Distance to Frontier, Selection and Economic Growth." unpublished, MIT 2002.

Acemoglu, Daron, Simon Johnson, and James A. Robinson. "The Colonial Origins of Comparative Development: An Empirical Investigation." American Economic Review 91 (December 2001): 1369-1401.

Acemoglu, Daron, and Fabrizio Zilibotti. "Productivity Differences." Quarterly Journal of Economics 116 (May 2001): 563-606.

Aghion, Philippe and Peter Howitt. "A Model of Growth through Creative Destruction." Econometrica, March 1992, 60(2), pp. 323-51.

Aghion, Philippe and Peter Howitt. Endogenous growth theory. Cambridge, MA: MIT Press, 1998.

Arrow, Kenneth J. "Classificatory Notes on the Production and Transmission of Technological Knowledge." American Economic Review Papers and Proceedings 59 (May 1969): 29-35.

Azariadis and Drazen. "Threshold Externalities in Economic Development." Quarterly Journal Of Economics, May 1990, 5 (105), 501-526.

Barro, Robert J., and Xavier Sala-i-Martin. "Convergence." Journal of Political Economy 100 (April 1992): 223-51.

Basu, Susanto, and David N. Weil. "Appropriate Technology and Growth." Quarterly Journal of Economics 113 (November 1998): 1025-54.

Baumol, William. "Productivity Growth, Convergence, and Welfare." American Economics Review, December, 76, (1986): 1072-1085.

Becker, Gary and Robert J. Barro. "Fertility choice in a model of economic growth." Econometrica, 1989, 76, 481-501.

Becker, Gary, Kevin Murphy, and Robert Tamura. "Human Capital, Fertility, and Economic Growth." Journal of Political Economy, October 1990, 95 (5).

Benabou, Roland. "Equity and Efficiency in human capital investment: the local connection." Review of Economic Studies, 1996.

Benhabib, Jess, and Mark M. Spiegel. "The Role of Human Capital Economic Development: Evidence from Cross-Country Data." Journal of Monetary Economics 34 (October 1994): 14373. 
Bloom, David, and Williamson, J. "Demographic Transitions and Economic Miracles in Emerging Asia," World Bank Economic Review, 1998 , 12(3): 419-55.

Caselli, F., Esquivel, G. and Lefort, F. "Reopening the Convergence Debate: A New Look at CrossCountry Growth Empirics," Journal of Economic Growth, September 1996, 1 (3), 363-389.

Cohen, Wesley M., and Daniel A. Levinthal. "Innovation and Learning: The Two Faces of R\&D." Economic Journal 99 (September 1989): 569-96.

Cohen, Wesley M., and Daniel A. Levinthal. "Absorptive Capacity: A New Perspective on Learning and Innovation." Administrative Science Quarterly 35 (March 1990): 128-52.

Crosby, Alfred. Ecological Imperialism: The Biological Expansion of Europe 900-1900. Cambridge University Press, New York, NY, 1986.

Durlauf, Steven N. "Nonergodic economic growth." Review of Economic Studies, 1993, 60, 349-367.

Durlauf, Steven N. "A theory of persistent income inequality." Journal of Economic Growth, 1996, $1,75-94$.

Durlauf, Steven N., and Paul A. Johnson. "Multiple Regimes and Cross-Country Growth Behavior." Journal of Applied Econometrics 10 (Oct.-Dec. 1995): 365-84.

Easterly, William, and Ross Levine. "It's Not Factor Accumulation: Stylized Facts and Growth Models." World Bank Economic Review 15 (2001): 177- 219.

Evans, Paul. "Using Cross-Country Variances to Evaluate Growth Theories." Journal of Economic Dynamics and Control 20 (June-July 1996): 1027-49.

Evenson, Robert E., and Larry E. Westphal. "Technological Change and Technology Strategy." In Handbook of Development Economics, edited by T. N. Srinivasan and Jere Behrman, 2209-99. Handbooks in Economics, v.9. Vol. 3A. Amsterdam: Elsevier, 1995.

Feyrer, James. "Convergence by Parts", November 2001, mimeo.

Galor, Oded. "Convergence? Inferences from Theoretical Models." Economic Journal 106 (July 1996): 1056-69.

Galor, Oded, and D. Tsiddon. "The distribution of human capital and economic growth." Journal of Economic Growth, March 1997, pp. 93-124.

Galor, Oded, and David Weil. "The Gender Gap, Fertility, and Growth." American Economic Review, June 1996.

Galor, Oded, and J. Zeira. "Income Distribution and Macroeconomics." Review of Economic Studies, 1993, pp. 35-53.

Gerschenkron, Alexander. "Economic Backwardness in Historical Perspective." In The Progress of 
Underdeveloped Areas, edited by Bert F. Hoselitz. Chicago: University of Chicago Press, 1952. Griffith, Rachel, Stephen Redding, and John Van Reenen. "Mapping the Two Faces of R\&D: Productivity Growth in a Panel of OECD Industries." unpublished, August 2001.

Hall, Robert E. and Charles I. Jones. "Why Do Some Countries Produce so Much More Output per Worker than Others?" Quarterly Journal of Economics, February 1999, 114(1), pp. 83-116. Howitt, Peter. "Endogenous Growth and Cross-Country Income Differences." American Economic Review 90 (September 2000): 829-46.

Howitt, Peter and Philippe Aghion. "Capital Accumulation and Innovation as Complementary Factors in Long-Run Growth." Journal of Economic Growth, June 1998, 3(2), pp. 111-130.

Islam, Nazrul. "Growth Empirics: A Panel Data Approach." Quarterly Journal of Economics, November 1995, 110(4), pp. 1127-70.

Klenow, Peter J. and Andrés Rodríguez-Clare. "The Neoclassical Revival in Growth Economics: Has it Gone too Far?" in Ben Bernanke and Julio Rotemberg, eds., NBER macroeconomics annual1997. Cambridge, MA: MIT Press, 1997, pp. 73-103.

Jacob, Margaret C. Scientific Culture and the Making of the Industrial West. New York: Oxford University Press, 1997.

Knight, Malcolm; Loayza, Norman; Villanueva, Delano. "Testing the Neoclassical Theory of Economic Growth: A Panel Data Approach," IMF Staff Papers, September 1993, 40 (3), 512-41.

Kremer, Michael, Alexei Onatski, and James Stock. "Searching for Prosperity." Carnegie-Rochester Conference Series on Public Policy 55 (2001): 275- 303.

Maddison, Angus. The World Economy: A Millennial Perspective. Development Centre Studies. Paris: OECD, 2001.

Maloney, W.F. "Technology, Growth and Resource Abundance Observations from Latin America", World Bank, mimeo, 2002.

Mankiw, N. Gregory, David Romer, and David N. Weil. "A Contribution to the Empirics of Economic Growth." Quarterly Journal of Economics 107 (May 1992): 407-37.

Mayer, D. "Convergence Clubs in Cross-Country Life Expectancy Dynamics." Discussion Paper No. 2001/134, World Institute for Development Economics Research, United Nations University, 2001.

Mayer, D. "Divergence Today." Documento de Trabajo del CIDE, División de Economía, forthcoming, 2002

Mowery, David C., and Nathan Rosenberg. Paths of Innovation: Technological Change in 20th- 
Century America. New York: Cambridge University Press, 1998.

Murphy, Kevin M., Andrei Shleifer, and Robert W. Vishny. "Industrialization and the Big Push." Journal of Political Economy 97 (October 1989): 1003-26.

Nelson, Richard, and Edmund S. Phelps. "Investment in Humans, Technological Diffusion, and Economic Growth." American Economic Review 56 (March 1966): 69-75.

Parente, Stephen L., and Edward C. Prescott. "Technology Adoption and Growth." Journal of Political Economy 102 (April 1994): 298-321.

Parente, Stephen L., and Edward C. Prescott. "Monopoly Rights: A Barrier to Riches." American Economic Review 89 (December 1999): 1216-33.

Pipitone, Ugo. "La salida del atraso: Un estudio histórico comparativo" Fondo de Cultura Económica, México, segunda edición, 1995.

Prescott, Edward C. "Needed: A Theory of Total Factor Productivity." International Economic Review 39 (August 1998): 525-51.

Pritchett, Lant. "Divergence, Big-Time." Journal of Economic Perspectives 11 (Summer 1997): $3-17$.

Quah, Danny T. "Empirical Cross-Section Dynamics in Economic Growth", European Economic Review, 1993, 37, pp.426-34.

Quah, Danny T. "Empirics for Growth and Distribution: Stratification, Polarization, and Convergence Clubs", Journal of Economic Growth,1997, 2, pp.27-59.

Rosenberg, Nathan, and L. E. Birdzell Jr. How the West Grew Rich: The Economic Transformation of the Industrial World. : Basic Books, 1986.

Tsiddon, D. "A moral hazard trap to growth." International Economic Growth, 1992, 33, 299-322.

Whitehead. Science and the Modern World. New York: Macmillan, 1931.

Wright, Gavin. "Can A Nation Learn? American Technology as a Network Phenomenon." In Learning by Doing in Markets, Firms, and Countries, edited by Naomi R. Lamoreaux, Daniel M. G. Raff, and Peter Temin, 295-326. Chicago: University of Chicago Press (for NBER), 1999. Zilibotti, Fabrizio. "A Rostovian Model of Endogenous Growth and Underdevelopment Traps." European Economic Review 39 (October 1995): 1569-1602. 


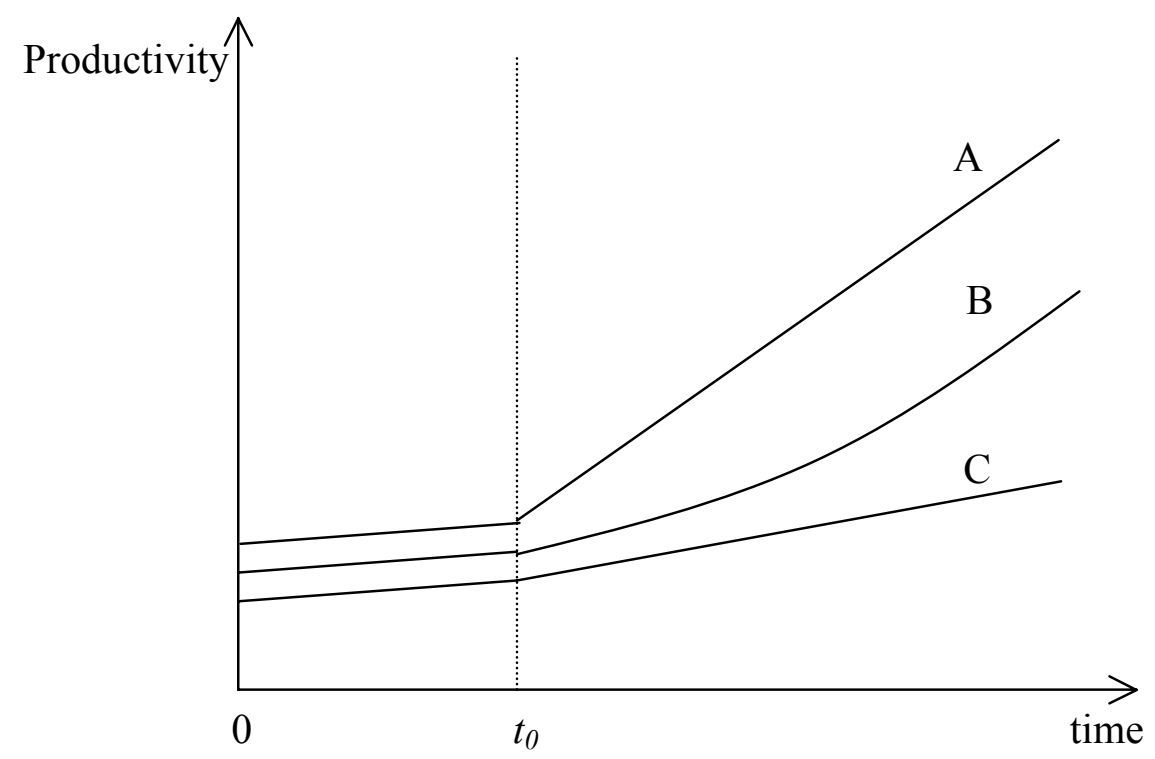

Figure 1 


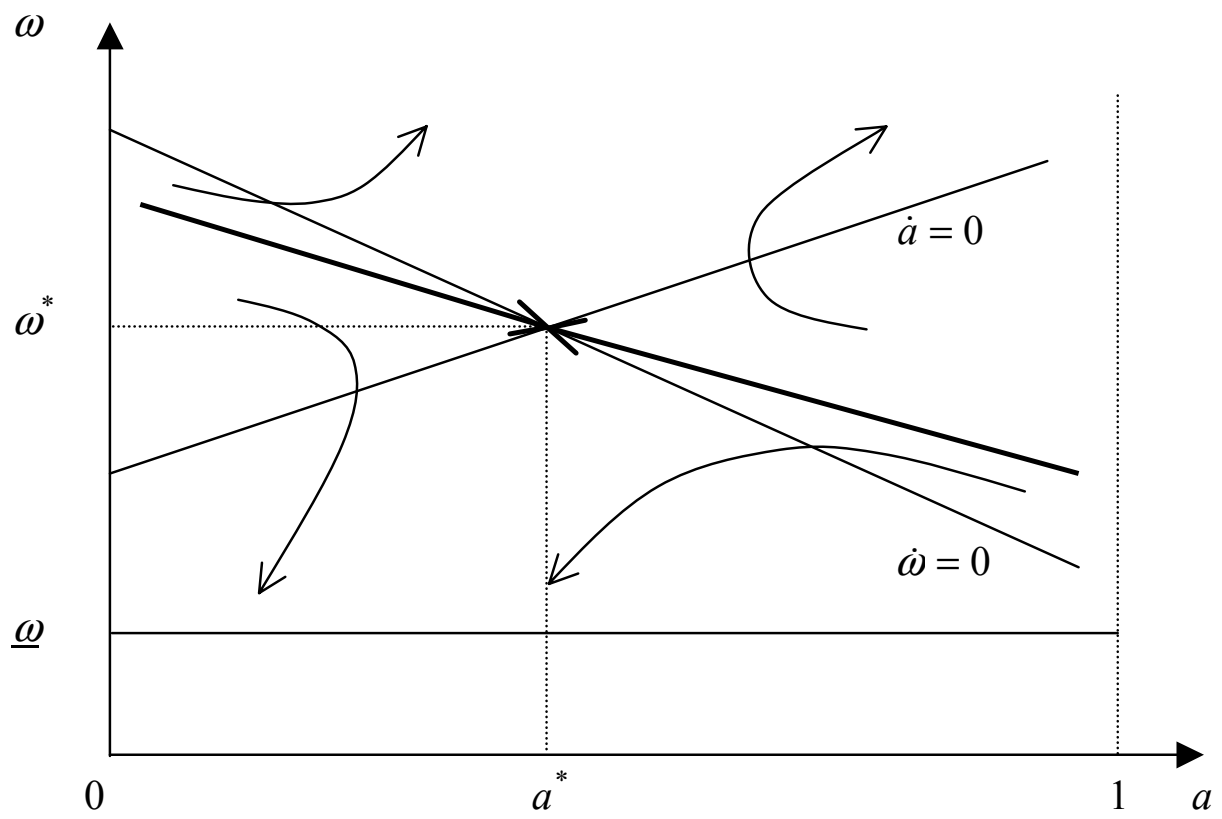

Figure 2a Interior steady state with growth rate g.

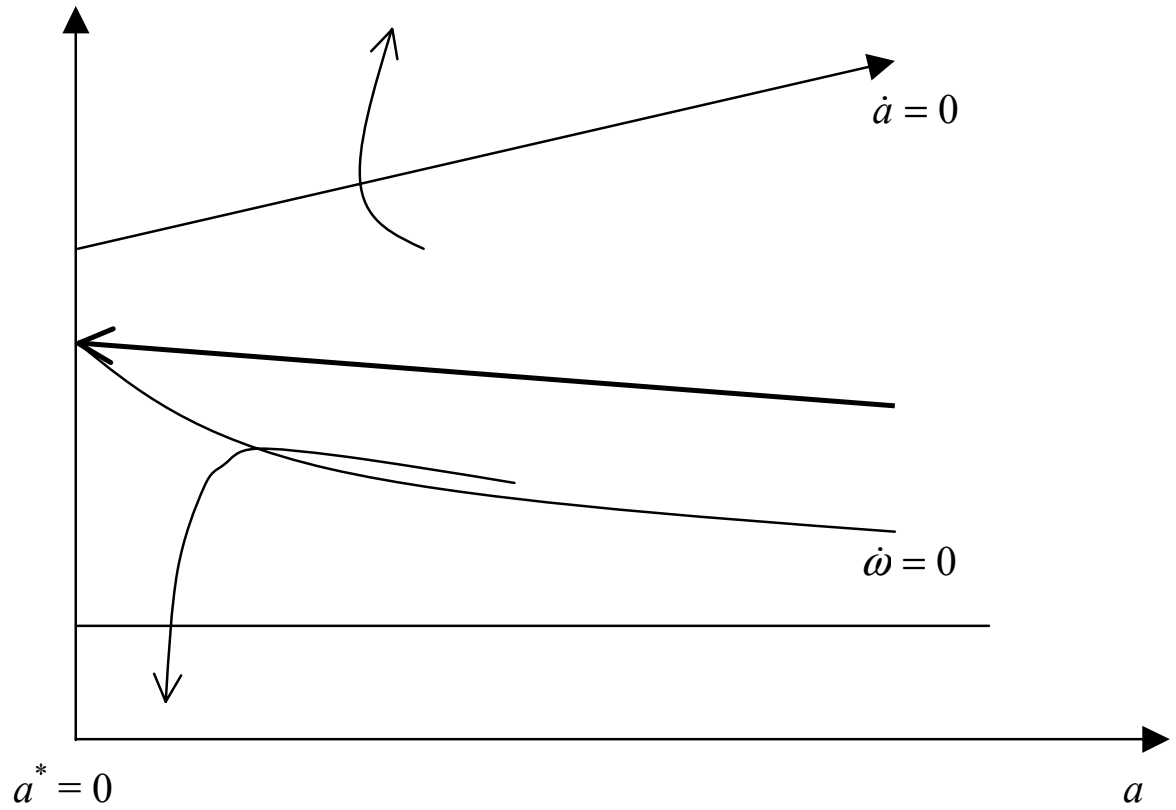

Figure $2 \mathrm{~b}$ Steady state with growth rate $\in(0, \mathrm{~g})$ 


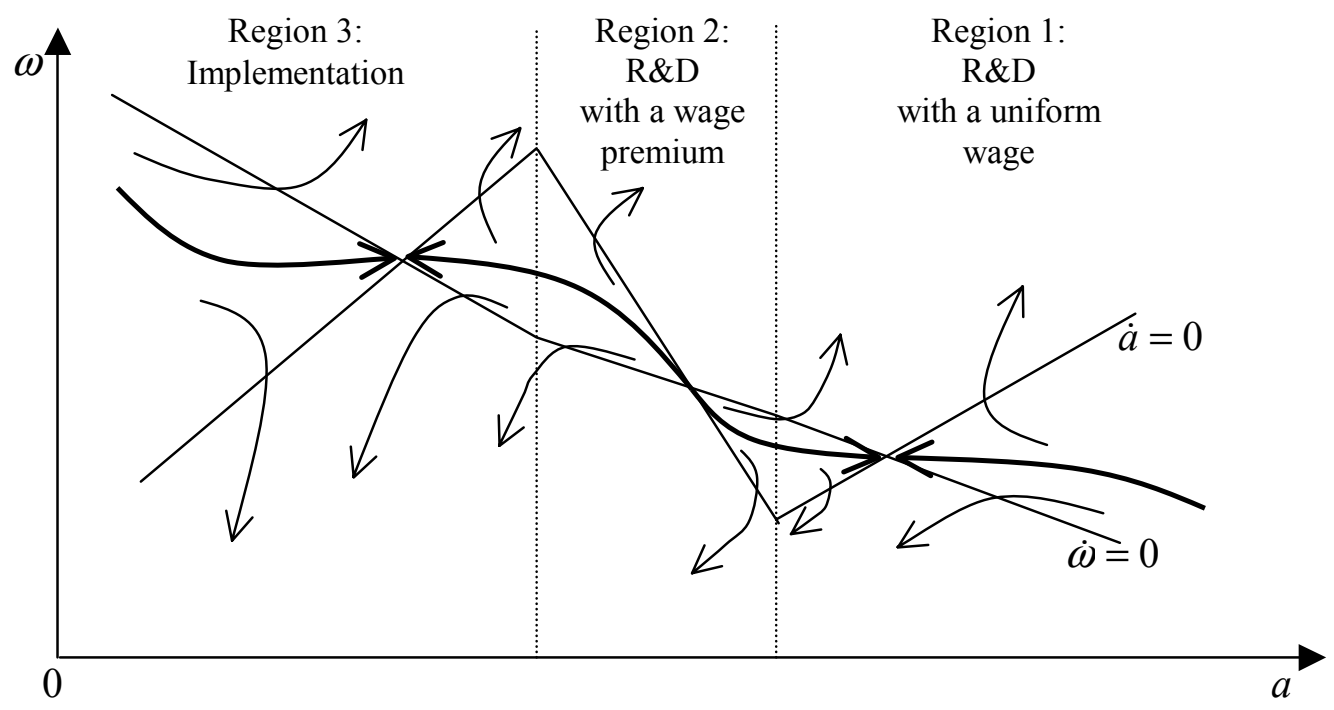

Figure 3. Modern R\&D. A case of multiple steady states. 


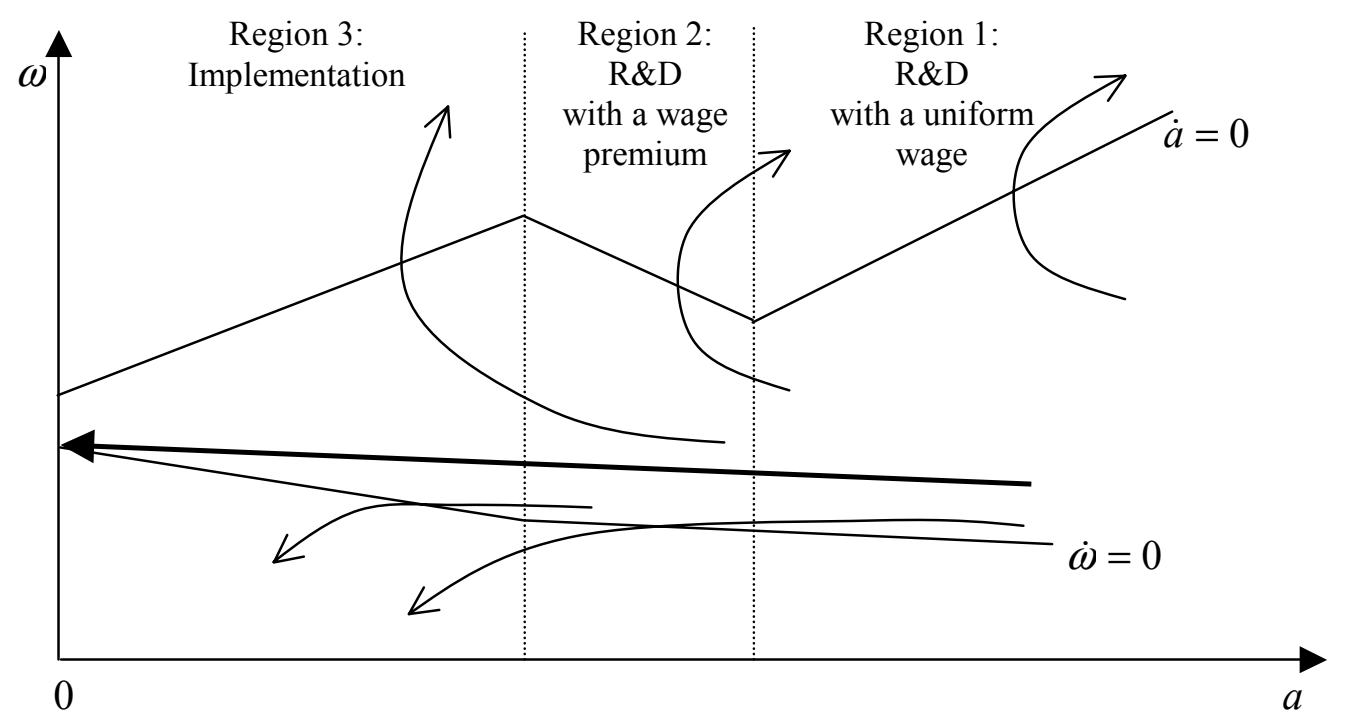

Figure 4. A case of a unique "stagnation" steady state. 


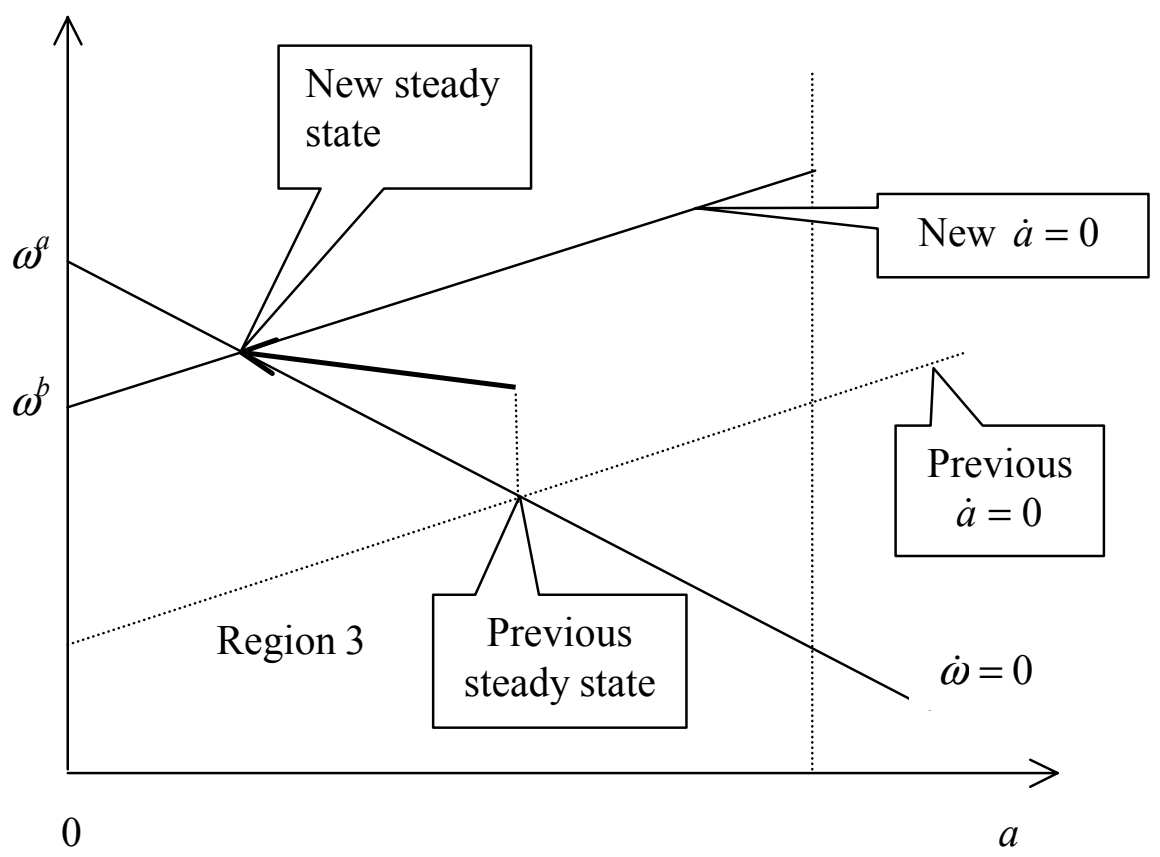

Figure 5: A country that starts in Region 3 must go to an implementation steady state (as illustrated) or to stagnation (if $\omega^{a}<\omega^{b}$ ). 


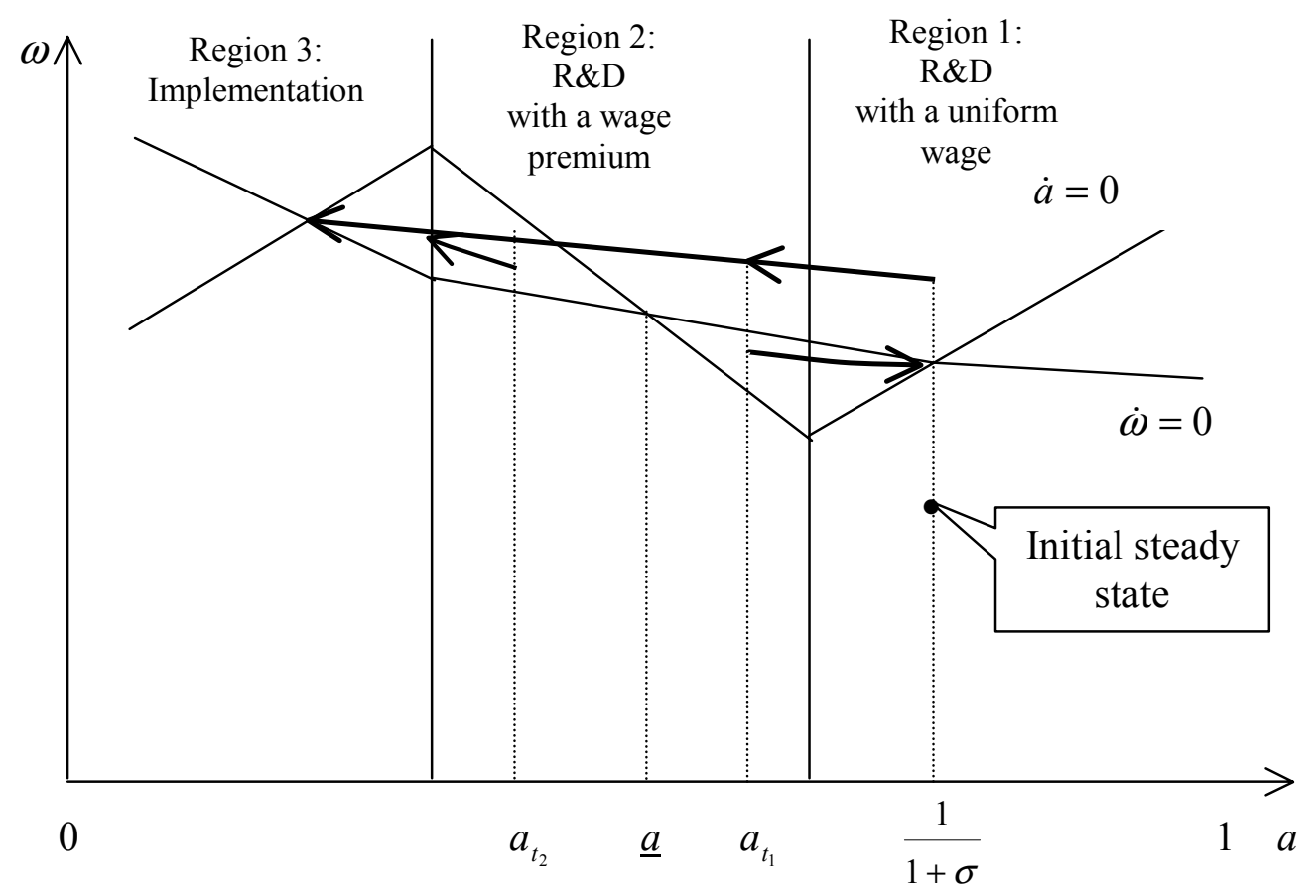

Figure 6: Windows of opportunity. If the country adopts the institutions supporting modern R\&D before its normalized productivity falls below $\underline{a}$, it can reverse course and move to the $R \& D$ steady state. Otherwise it will become trapped in the implementation (or stagnation) region 3. 